\title{
NISTIR 6805
}

\section{Optical Current Transducers for Electrical Power Systems: Overview and Literature Survey}

Simmon, E.

U. S. DEPARTMENT OF COMMERCE Technology Administration National Institute of Standards and Technology

Electricity Division

Gaithersburg, MD 20899

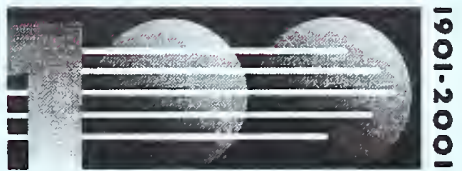

NIST CENTENNIALE
QC

\section{0}

.U56

NO.6805

2001

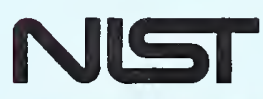

National Instifute of Standards and Teehnology Technology Administration U.S. Department of Commerce 


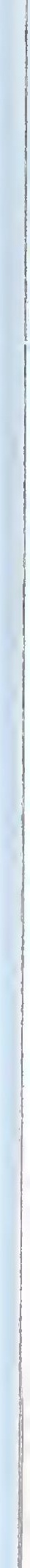




\section{Optical Current Transducers for Electrical Power Systems: Overview and Literature Survey}

Simmon, E.

U. S. DEPARTMENT OF COMMERCE Technology Administration

National Institute of Standards and Technology

Electricity Division

Gaithersburg, MD 20899

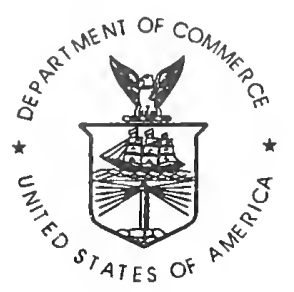

U.S. DEPARTMENT OF COMMERCE Donald L. Evans, Secretary

NATIONAL INSTITUTE OF STANDARDS AND TECHNOLOGY

Dr. Karen H. Brown, Acting Director 


$y_{1}$
$y_{1}$




\section{Abstract}

A literature survey of Optical Current Transducers (OCTs) with particular emphasis on electric power systems measurements has been performed. This report is intended to provide information based upon the published literature on the various types of OCTs and their application to power systems. It contains an annotated bibliography of almost two hundred references either directly or indirectly related to power system applications. The bibliography includes a listing for each paper, an abstract, and its power system application or possible application. Preceeding the bibliography is a discussion of the different OCT types, their operating principles, measurement errors, and their application for electric power systems including metering, relaying, and diagnostic applications. 


\section{Disclaimer}

The identification of any commercial productor trade name does not imply endorsment of recommendation by the National Institue of standards and technology.

The policy of the National Institute of standards and technology is to use metric units of measurement in all its publications. In this document however, works of authors outside NIST are cited which describe measurements in certain non-metric units. 


\section{Table of Contents}

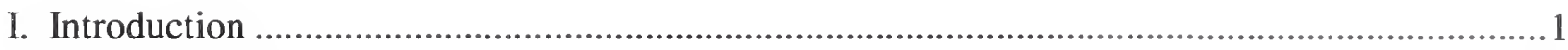
A. Purpose

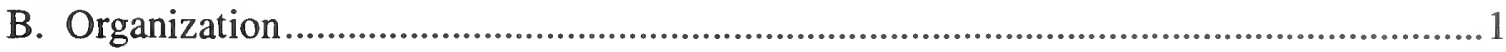

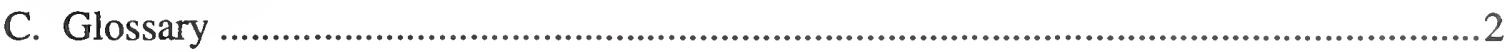

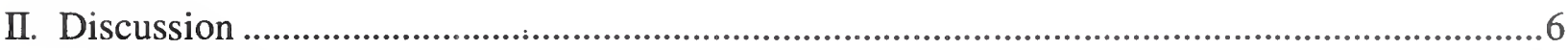

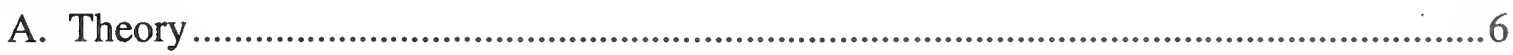

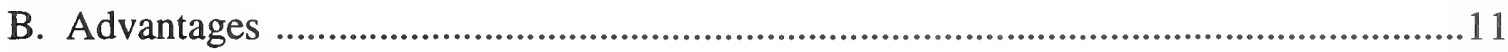

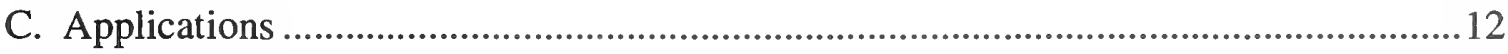

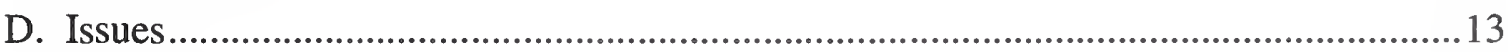

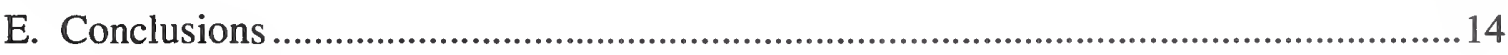

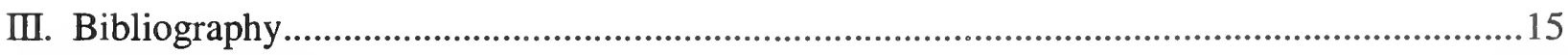

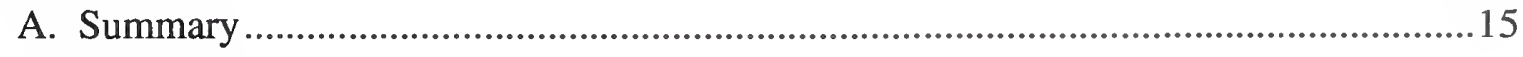

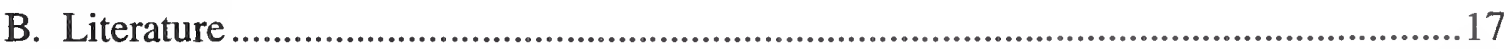

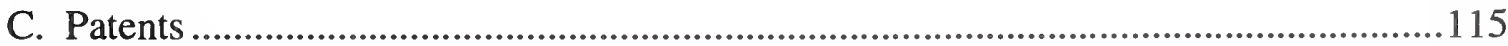

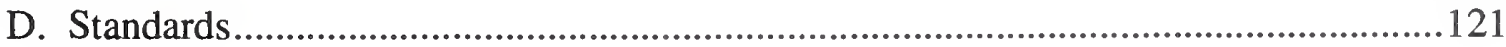


: 


\section{Introduction}

\section{A. Purpose}

This report has been prepared by staff at the National Institute of Standards and Technology for the purpose of assessing the state of optical current transducer (OCT) development for use in electric power systems. It builds on the foundation created by the NIST Tech Note 1307 [51], EPRI report EL5431 [52] produced by the NIST Optoelectronics Division and the EPRI report EL5431 [79] produced by the NIST Electricity Division ${ }^{1}$. The first two papers present a detailed analysis of the absolute limits of optical current and optical voltage sensors, while the last paper presents an assessment of the future of optical current and optical voltage measurements including a survey of utilities and manufacturers.

Many papers have been published on field testing of prototype and production optical current transducers and even more have been published discussing the basic principles and limitations of Faraday effect devices. This bibliography is intended to help those interested in applying optical techniques to current measurements for power systems sort through the vast amount of papers and obtain an understanding of the operation of OCTs and their application to power systems. The focus of this report is on optical current sensors with intended or demonstrated applications in power systems for metering, fault sensing (relaying), and diagnostics with a secondary emphasis on the fundamental limits of these devices.

\section{B. Organization}

This report is divided into three sections. The first section discusses the organization and content of the bibliography. The second section is a brief overview of OCT designs and their application to power systems. A summary is included of the current state of the art for OCTs used in the electric power industry with references to many of the papers in the bibliography. The third section consists of the bibliography itself and is separated into four parts: A short introduction, papers covering OCT theory, development and testing, patents (from 1976 to 1999) for devices using the Faraday effect for current measurement, and standards covering the use of conventional current transformers (CTs) and OCTs in electric power systems. Only papers published in English were reviewed, but some papers published in other languages are included in the OCT section. These entries are denoted by an additional language field following the year of publication in the citation.

\footnotetext{
${ }^{1}$ REFERENCES ARE PRESENTED IN ALPHABETICAL ORDER ACCORDING TO LEAD AUTHOR, NOT IN ORDER OF APPERANCE IN THE TEXT.
} 


\section{Glossary}

To assist the reader in using this document some of the commonly used terms are defined below.

Annealed fiber sensor

Bus bar

Bushing

Circular

birefringence

Concentrator ring

Dielectric

Faraday effect
A fiber optic sensor that has undergone an annealing process to reduce stress-induced birefringence due to the bending of the fiber.

A conductor that serves as a common connection between two or more circuits in a substation or generating plant.

A dielectric component, generally ceramic, for isolating a high voltage conductor from ground or another conductor.

The property of an optically transparent material having a different index of refraction for left circularly polarized light and right circularly polarized light.

Note: If a beam of linearly polarized light is passed through the optical material, the velocity of the l-circular component is different than that of the r-circular component of light. Since linearly polarized light is composed of a r-circular component and a l-circular component, the net effect of circular birefringence on a linearly polarized beam of light is a change in the plane of polarization of the beam.

A high permeability toroidal ring, usually made of iron, which has a small air gap in which an optically active material is inserted. Note: The current flows through the center of the ring and the ring produces an intensification of the magnetic field intensity $\mathrm{H}$ in the gap.

Any material characterized by a low conductivity.

An induced circular birefringence due to the presence of a magnetic field in an optical material.

Note: Linearly polarized light (electromagnetic wave) traveling through a dielectric material exhibits a rotation of the plane of polarization 
proportional to the applied magnetic field. The angle of rotation $(\theta)$ is given by:

$$
\theta=V \int \mathrm{B} \bullet \mathrm{dl} .
$$

where $V=$ Verdet constant, $B=$ magnetic flux density; $l=$ length.

Hi-bi fiber

Interferometric sensing

Linear birefringence

Non-reciprocal effects

Optical current

transducer
A number of different types of optical fiber that are constructed to provide very high linear birefringence so as to maintain the polarization of linearly polarized light. Some examples are: bowtie fiber, stress applying parts (SAP) hi-bi fiber, twisted hi-bi fibers.

Two beams of light traveling along different paths are combined at a point and the resulting interference pattern is analyzed.

The property of an optically transparent material having two characteristic orthogonal axes, a fast axis and a slow axis, each exhibiting a different index of refraction. Linearly polarized light will travel at a faster velocity if its electric field vector is aligned with the fast axis and slower if its electric field vector is aligned with the slow axis. Note: a linearly polarized beam not aligned with either of these axes will experience a change in polarization state, i.e., the linearly polarized beam can become elliptically polarized.

Effects in an optical medium that are dependent on the direction of light propagation. Example: Faraday effect (magnetic field)

A current measuring device that uses the induced changes in the properties of an optical element (sensor), and hence, the propagation of light through it. The optical signal is then converted to an electrical signal proportional to the current applied to the sensor. 
Polarimetric

sensing

Polarization

maintaining

fiber

Power quality monitoring

Reciprocal effects

Relaying

Revenue metering
A technique in which a single light beam travels through the sensor and is decoded by a polarizer (or pair of polarizers) at the output.

Fiber with optical characteristics designed to maintain the plane of polarization of light traveling through it.

The measurement of current and voltage in an electric power system to collect information on waveform deviations from a pure single frequency sinusoidal waveshape and a nominal amplitude.

Effects in an optical medium that are independent of the direction the light is propagating through the sensor. Examples: temperature, vibrational effects.

The process of measuring the real or reactive voltage, current, power, and/or energy flow in a power line for the purpose of protecting the equipment from damage due to overloads.

Note: The information is used to trigger relays that divert the overload current. Measurement uncertainties do not need to be very low as long as the relays trip in a timely manner.

The process of measuring the power or energy at a transition point in a power system for the purpose of billing.

Note: The current and voltage are measured separately and then are input into the power or energy meter. Low measurement uncertainties are important to lower billing errors.

A sensor using the Sagnac interferometric design which has a reflector at one end to return light along the incident optical path to the detector.

Sagnac interferometer
A sensor design were light travels in both directions through an optically active sensor element and is combined at the output. If a magnetic field is applied, one beam will travel around the loop faster 
than the other. When the two beams are combined at the output, a phase shift relative the the magnetic field can be measured.

Sagnac loop sensor

A Sagnac interferometric design which uses a loop of fiber with counter propagating beams; light is injected and detected at both ends.

Verdet constant

A scalar constant of proportionality equal to the rotation of linearly polarized light per unit path per unit magnetic field strength.

Note: The angle of rotation $\theta$ is related to the magnetic field strength $\mathrm{H}$ through the Verdet constant. If the magnetic field is uniform, $\theta=$ $\mathrm{V} \mu \mathrm{Hl}$. The Verdet constant is a measure of the sensitivity of the optical material to magnetic fields. 


\section{Discussion}

A. Theory

Although there are many different types and combinations of sensor configurations and detecting schemes, the basic operation of an optical current transducer is relatively simple. The current flows down the conductor, creating a magnetic field around it. If a magneto-optic material is placed in the magnetic field, then circular birefringence is induced in the material. This circular birefringence can be measured by transmitting a beam of linearly polarized light through the optical material and observing the change in polarization as it emerges from the material. Using the relationship between the current flowing in the conductor and the magnetic field, along with the relationship between the magnetic field and the induced circular birefringence in the magneto-optic material, the current can be calculated from the change in polarization. Different decoding methods may be used to convert the light signal at the output of the sensor into a signal representing the current traveling through the conductor.

One thing all these sensors have in common is the Faraday effect. The following paragraphs describe the Faraday effect in a simple one turn, closed loop, bulk glass or fiber sensor. Current in a conductor induces a magnetic field around the conductor. If the conductor is a infinitely long round wire, surrounded by air, the magnitude of the magnetic field $(B)$ is constant at a distance $r$ from the wire axis, with $B$ equal to:

$$
B=\frac{\mu_{0} I}{2 \pi r},
$$

where $\mu_{0}$ is the magnetic permeability of air, $I$ is the current flowing in the conductor, $r$ is the distance from the wire. It can be seen from Eq. (2), that if the magnetic field caused by the conductor current can be measured, the current can be determined.

By utilizing the Faraday effect, a magneto-optic effect in which a circular birefringence in an optical material is induced by an applied magnetic field, the magnetic field and indirectly the current can be measured. If linearly polarized light (which has both right-circularly polarized and left-circularly polarized components) is launched down an optical material exhibiting the Faraday effect, the circularly polarized components travel at different speeds and their phase relationship changes. The result is a change of the plane of linear polarization as the light travels through the sensor medium. This angle of rotation of this plane is given by: 


$$
\theta=V \int B \bullet d l
$$

where $V$ is the Verdet constant (see glossary), $B$ is the magnetic flux density, and $d l$ is the incremental path length. If $B$ is constant over the length of the sensor, then the device can be used as a magnetic field sensor. Eq. (2) becomes $\theta=V B l$, with $l$ being the length of the sensor, and the angle of rotation is directly proportional to the magnetic field. Such a device can also be used as a current sensor if there is a simple relationship between the magnetic field in the sensor and the current producing the field. However, this type of sensor is sensitive to all magnetic fields (including those due to other current sources) contributing to $B$ at the sensor.

A sensor that detects only the magnetic field due to the current in the conductor passing through it can be designed by forming a closed loop around the current carrying conductor. If the magnetic field is integrated in a loop enclosing the conductor, the result is proportional to the

$$
\int \mathrm{B} \bullet \mathrm{dl}=\mu_{\mathrm{o}} \mathbf{I}_{\text {enciosed }}
$$

enclosed current. This is based on Ampere's law,

which states that the path integral of $B \bullet d l$ around any closed loop is equal to the current, $I_{\text {enclosed, }}$ enclosed by the loop multiplied by the magnetic permeability $\mu_{\mathrm{o}}$.

Applying Ampere's law to Eq. (2) it becomes:

$$
\theta=\mu_{o} V I_{\text {enclosed }} \text {, }
$$

where $\mu_{\mathrm{o}}$ is the permeability of the optical glass fiber or bulk glass, the same as the permeability of free space. Generally the Verdet constant is small, so a single loop silica glass sensor is useful only for fairly large currents. For example, a current of $10 \mathrm{kA}$ passing through such a sensor will produce a rotation of less than 5 milliradians. The sensitivity can be increased by increasing the number of loops of the light path around the conductor. For a light path that consists of $\mathrm{N}$ turns around the conductor, Eq.(4) becomes

$$
\theta=\mu_{o} N V I_{\text {enclosed }},
$$

The sensitivity of the sensor can also be increased by using a material with a larger Verdet constant. Materials such as flint glass have Verdet constants that are an order of magnitude or more larger than that of silica glass.

The theoretical advantages of the closed-loop design can be seen by examining Eq. (5). First, the 
angle of rotation is sensitive only to the net current that passes through the sensor and is immune to fields due to currents outside the sensor so that unwanted pickup of external signals is minimized. Second, the sensitivity of the device can be tailored to the measurement application by selecting the appropriate number of loops $N$ of the sensor or using a material with a different Verdet constant $V$. Measurement of large current requires a small $N$ and $V$; small currents need larger $N$ and $V$ to operate the sensor in the linear range where $\sin \theta \approx \theta$. Third, the angle of rotation is independent of where the conductor is positioned within the sensor; positional sensitivity, which can be a problem with conventional current transformers, is thereby minimized.

The optical sensors are implemented using a variety of different optical materials and different sensing schemes. The types of optical sensing elements can be grouped into several categories: bulk glass (silica or doped glasses) $[19,136,181]$, waveguide $[121,122,123,124]$, or fiber [15, 16] thin film crystals (such as yttrium iron garnet $[90,161]$ ). However, most optical materials exhibit the Faraday effect to some degree. In fact, sensors using liquid as the Faraday effect sensing element have been built [72]. The decision on what type of sensing material to use is a difficult one. Silica bulk glass sensors are simple and inexpensive, yet are limited by a small Verdet constant [51]; therefore doped glass [98] or other crystals [89] which have increased sensitivity are usually used even though it is more costly. Similarly, single-turn silica fiber sensors have low sensitivity yet are easy to produce. By increasing the number of fiber turns, the sensitivity may be increased at the same time but additional steps must be taken to reduce stress birefringence, which increases cost and manufacturing difficulties. Thin film crystals such as yttrium iron garnet have large Verdet constants and show great potential, but the ferromagnetic material suffers from temperature dependence and hysteresis effects [161]. Several sensing configurations are also in use. The simplest configuration is a polarimetric design $[34,63,68$, $109,116,181]$ using one or two analyzers at the output. More complex than polarimetric designs, interferometer based designs, which use two beams to create an interference pattern at the output, hold great promise as well $[15,44,67,105,130,151]$.

These sensing elements may be constructed in a variety of sensor configurations using different decoding schemes. Bulk glass sensor heads come in square [7, 31, 181], triangular [39, 40, 69] and round $[\mathrm{REF}]$ shapes which encircle the current carrying conductor. Fiber sensors are formed by bending an optical fiber in one or more loops [54]. Sometimes a magnetic flux concentrator is used to provide a closed loop around the conductor and eliminate the effects of external fields $[36,84,85,137]$. Sensors that do not form a closed loop around the conductor are actually magnetic field sensors, not current sensors, and are sensitive to external fields

Due to the complex nature of the OCT, many error sources contribute to the measurement uncertainties for these devices. It is important to minimize the effects of these sources to achieve reasonable uncertainties. If the sensor is to be used for metering applications, these effects must have an amplitude much smaller than the measured signal. The major sources of uncertainty are discussed below. 
The limits of uncertainty are determined by a combination of noise sources, i.e., random effects and errors due to systematic effects. Some of the types of noise are spectral noise due to the light source and shot noise that are present in the photodetector circuit. These noise sources reduce the sensitivity of the sensor to smaller currents, but for single frequency metering in power systems their effects can be reduced by filtering the detector output.

The Verdet constant is a major source of uncertainty because it exhibits both temperature and spectral dependence. The temperature dependence of the Verdet constant is largest in ferromagnetic materials and smallest in diamagnetic materials (but still large enough to be significant in current sensors). For many other applications, the effect of temperature dependence of the Verdet constant of diamagnetic materials can be considered to be negligible. This is not the case for the OCT, where even a small change in Verdet constant can cause a measurable error [51]. For low uncertainty measurements, a variety of temperature compensation methods may be used $[20,55]$.

The Verdet constant also exhibits spectral dependence, where according to the classic Becquerel formula, it is inversely proportional to the wavelength of the light propagating through the sensor. If a current is passing through the sensor, a change in wavelength of the light source would change the detector output, which would be interpreted as a change in current. Since the wavelength of the light source depends on temperature, it is important that the source be temperature-stabilized to achieve the lowest measurement uncertainties.

Another source of uncertainty in OCTs is the limitation of the mathematical model. The model for optical current transducers using Ampere's law is only correct if the sensing element forms a closed loop and does not account for the leads and other elements in the optical path. Most sensors have small sections of optically sensitive material between the polarizers and the closed loop encircling the conductor [51]. These sections may also be sensitive and exposed to magnetic fields and thus influence the polarization of light propagating through them, but are not included in the idealized model of Eq. (6). A sensor exhibiting this external sensitivity will have a slight positional dependence, along with a sensitivity to magnetic fields from sources other than the current passing through the conductor.

The non-ideal nature of the sensor head (bulk glass or fiber) can introduce error into the measurement. The effect of the linear birefringence is to reduce the sensitivity of the sensors to the current [51]. The most troubling form of linear birefringence is stress-induced birefringence, where a force applied to the sensing element causes the index of refraction along one axis to be greater than the index of refraction along the other axis. This is usually insignificant in bulk glass sensors, but fiber sensors with one or more loops of fiber can have large amounts of stress-induced birefringence due to the bending of the fiber especially for small diameter loops [162]. Two methods for reducing this birefringence are twisting the fiber $[70,149,173]$ and annealing the fiber $[50,118]$.

In addition to the uncertainty sources related to the sensor head, the optics and electronics used in the device are potential error sources $[51,52,109]$. The spectral quality of the sensor is affected 
by the light source and the polarizers, beam splitters, and waveplates used. The photodetector and amplifier electronics can add noise and distort the output of the sensor. Applications such as fault monitoring and diagnostics generally do not require low measurement uncertainties so that noise effects are tolerable, but require a large dynamic range. Metering applications require the lowest uncertainties, so for these applications noise can be minimized by signal processing techniques while errors can be minimized by construction techniques [108, 145, 156, 159] and error compensation $[10,119,144]$. 


\section{B. Advantages}

Unlike a conventional current transformer, OCTs are not limited by the physical properties of an iron core. The limits imposed by the sensor (the optical element) are much different than those imposed by the core and windings of a conventional current transformer. The iron core in a current transformer limits the dynamic range and frequency response of the transformer. The frequency response of the OCT is limited by the time it takes the beam of light to travel through the sensor and the dynamic range is limited by the electronics used to decode the sensor output.

The cost of a current transformer for use in high voltage environments increases greatly as the voltage increases. This is due to the increased cost of an insulation capable of withstanding the higher voltages [79]. Since the insulator for an OCT is merely a non-conductive stand for the OCT sensor head, this cost increases with voltage at a much lower rate compared to traditional CT insulators which must protect a conductor which runs within the insulator. The OCT unit including insulator is much smaller than conventional CTs and requires less manpower for installation on a line.

The small size and light weight of the OCT make it ideal for troubleshooting equipment and transmission line problems. By using discrete bulk glass components, clamp-on sensors have been constructed which can be clamped on a conductor without breaking it (and without de-energizing the conductor) $[7,134,135,144,171]$. These sensors can be moved into place when needed to make diagnostic measurements.

The frequency response of an OCT is limited by the distance the polarized light must travel through the sensing unit [60]. This gives a theoretical limit of approximately $10^{\circ} \mathrm{Hz}$ for a single loop sensor (fiber or bulk glass) which is many orders of magnitude larger than that of conventional CTs. The high frequency rolloff of the detector electronics makes the practical limit much lower, but a tradeoff can be made in the electronics compromising dynamic range for bandwidth depending on application. The OCT is also capable of working all the way down to dc [40, 99, 143], so the wide bandwidth of the OCT provides more information about signal quality than is obtainable with narrow bandwidth CTs [36].

If larger uncertainties are acceptable, a fringe-counting decoding scheme can be used to give an extremely large dynamic range. Metering sensors typically operate in the relatively linear region where $\theta$ is much less than $\pi / 4$ and $\sin (\theta) \approx \theta$. However, for large currents the plane of polarization can be rotated beyond this quasilinear region. If the plane of polarization rotates multiple times, these rotations can be counted. This is referred to as fringe counting. While fringe counting is not as easy to implement and has greater uncertainties, it may be used to provide overcurrent protection monitoring output from a metering sensor. 


\section{Applications}

There are three areas where the advantages of the OCT make them an attractive alternative to conventional technology used in electric power systems; metering applications, fault monitoring, and equipment diagnostics.

Fault monitoring has much less demanding requirements than metering in terms of the uncertainties required $[28,190]$. The most important parameters in a relaying sensor are dynamic range and broadband response to capture large amplitude transients. There are several manufacturers producing simple low cost sensors designed for relaying. These sensors have much larger uncertainties and require little temperature or vibration compensation; they therefore are simple in design and inexpensive to produce [85, 193].

Metering is the most demanding application for OCTs, requiring the lowest uncertainty and highest stability and linearity $[79,89]$. The low uncertainties needed for metering using an OCT require compensation for errors due to temperature, vibration, and electronics noise and drift [51]. The increased sophistication of OCTs designed for metering raises the production costs compared to OCTs designed for relaying.

Equipment diagnostics and current quality monitoring have different requirements than metering or relaying [79]. The monitoring sensor must provide information about the harmonic signature of the current which will help to determine the condition of the equipment and possibly predict any potential failures that may occur. Analyzing the frequency content of the current waveform can be used to help determine the condition of the device. An example of this would be field-current monitoring for generators in a power plant $[73,172]$. In the past the quality of the current power plant generators was very difficult to measure. While this information is certainly useful, it will require the development of new techniques to understand all the information that will be available. It is important to notice that the unique design of the OCT allows one OCT to be used for all three types of measurements. This can be done by applying three different signal processors to the sensor output. For metering, a narrow bandwidth filter centered around the $60 \mathrm{~Hz}$ power frequency along with error compensation is useful in providing the required uncertainties for measuring the $60 \mathrm{~Hz}$ current component. The uncertainty requirement for relaying is much larger, less error compensation is needed, and nonlinearities of the response function are tolerated. In fact, eventually fringe counting may be used to provide a very large dynamic range, limited by the time response of the electronics. For equipment diagnostics, the output is a realtime signal used to evaluate the quality of the current waveform. With a large bandwidth being the main requirement, limited dynamic range and large uncertainties are acceptable. 


\section{Issues}

Optical current measurements show potential for revolutionizing how currents are measured on the power grid; however, the technology needs to be refined; error sources need to be eliminated and failure modes minimized [52]. In addition, the instruments need to be integrated with existing systems $[11,79,141]$.

The durability of OCTs has not been extensively tested [79], but there have been many field tests for monitoring [36,73, 172], fault location [23,90, 193], and metering [11, 141]. Unlike a current transformer (a passive device) the OCT is composed of many active electronic devices [178]. The light source, photodetector, and electronics all are sensitive semiconductor devices which might fail. While these components have improved over the last few years, whether the lifetime in a high voltage environment approaches that of conventional CTs has yet to be proven.

Lastly, the OCT must be integrated into existing systems before it can be used. Present power systems use meters designed to accept an input of $0 \mathrm{~A}$ to $5 \mathrm{~A}$ from a conventional CT. However, the extensive signal processing required by the OCT is usually done digitally. While this digital OCT signal can be converted to a large analog current output to be compatible with existing meters, uncertainties are increased due to the $\mathrm{D} / \mathrm{A}$ converter and power amplifier stages needed. The latest metering technology is based on digital circuitry and accepts a digital input. While this technology is still being developed, standards have not been established and existing standards are biased towards conventional transformers [S1, S2]. The industry is moving to an all digital metering system which will allow OCTs to be easily integrated [79, 141]. 


\section{E. Conclusions}

The basic principles of OCT have been analyzed thoroughly in a number of papers in the last 30 years $[10,51,153,158]$. The fundamental limits of OCTs are set by physical restrictions; they are primarily shot noise limitations in the detector electronics and frequency limitations due to the length of the sensor and the time it takes for the optical signal to travel through the sensing element. Errors due to temperature and vibration can be made negligible by using a variety of sensing schemes [144, 156, 181].

Prototype sensors have been developed which compete with conventional CTs in terms of uncertainties. At least three manufacturers have prototypes that are in this range [30, 33, 172]. Whether companies can mass-produce a metering class OCT remains to be seen.

While there are no metering-quality optical current transducers presently in large scale production (global production is presently in the hundreds), there are relaying OCTs being produced on a large scale (thousands of units) [176]. Units that provide metering accuracies are available for special applications from a handful of manufacturers and several OCTs are under development for large scale production.

The changing nature of the power grid in the United States as it becomes less regulated and more competitive might provide an improved market for this developing technology. The increased competition involved in generating/buying/selling power should make low uncertainty measurements more important [NIST IR 6007]. The number of points on the grid where metering-class current measurements are needed should increase along with the number of entities buying and selling power. Due to the complexity of the deregulated grid and numerous entities participating low uncertainty measurements will need to be made at a variety of new points between the generating station and the end user [NIST IR 6007].

The increased competition is driving the operators of the power grid to run closer to maximum capacity in an effort to maximize capacity [NIST IR 6007]. With the proliferation of electronic controllers that introduce harmonics onto the grid, and the dramatic increase in the number of sensitive electronic devices that has occurred in recent decades, it is very important to monitor the power quality of the grid so potential problems can be rectified before equipment failure occurs. 


\section{Bibliography}

A. Summary of Sections - Description of bibliography format.

\section{Section B, LITERATURE:}

Papers discussing optical current sensors. This includes papers describing laboratory work and papers which only present theory as well as papers presenting detailed descriptions of prototype sensors and field testing. Conference and archival papers are included here. Two additional fields have been added in each entry to assist the reader in digesting this material:

The first field is an "OCT type" field has been added which categorizes according to the following types:

Bulk glass Bulk glass (silica, doped glasses, and other crystals) is used to form the sensing element.

Fiber Optical fibers are used to form the sensing element.

Magnetic concentrator A magnetic concentrator ring with an optically active material placed in an air gap is used for the sensing element.

Hybrid A sensor using an optical sensor on the secondary of a conventional current transformer or rogowski coil.

Thin film

Integrated optics

Clamp on
Thin film crystals used for the optical sensing element.

A sensor with the optical components (polarizers, waveplates, etc.) formed on the waveguide along with the sensing element.

A sensor which can be disassembled and placed around a conductor without breaking the conductor. 
The second field is "Power Systems Relevance", which utilizes a three star system to rate the paper's relevance to high voltage power systems in the following manner:

General OCT papers including theory and experimental results for sensors not specifically designed for high voltage power systems.

OCT papers which mention high voltage power systems and have been designed with power systems applications in mind.

High voltage power system specific papers detailing either prototypes designed specifically for high voltage power systems or actual field testing of prototype or commercial devices for high voltage power systems.

Section C, PATENTS:

United States patents from 1976 to 1999 which describe the design of optical current transducers are covered.

Section D, STANDARDS:

U.S. and foreign standards are covered both conventional CTs and non-conventional devices such as OCTs. 


\section{B. Literature}

[1] Adolfsson, M., Einvall, C., Lindberg, P., Samuelsson, J., Ahlgren, L., and Edlund, H., "EHV Series Capacitor Banks. A New Approach to Platform to Ground Signaling, Relay Protection and Supervision.,"

IEEE Transactions on Power Delivery, Vol. 2, No. 2, pp. 1369-1376, April 1989.

Abstract:

This paper describes a new optoelectronic protection and supervision system for EHV series capacitor banks. The new system utilizes a novel fiber-optic current transformer concept. The new system is described, availability adaptations are discussed and results from fields tests an experience from a $400 \mathrm{kV}$ pilot installation are reported.

OCT type: Hybrid

Power systems relevance: $* * *$

[2] Afanas'ev, V.V. and Krastina, A.D.,

"Measuring Heavy Currents by a Contactless Method Based on the Faraday Effect," Elektrichestvo, Vol. 3, pp 37-40, March, 1978.

Abstract:

The development of optical methods for data transmission has opened up scope for use of optics in measuring heavy currents, e.g., on $750 \mathrm{kV}$ transmission lines. Some advantages of magneto-optical measuring transducers based on the Faraday effect are: quicker response, sensitivity to polarity and metrological properties independent of the level and type of voltage. A comparative study is made of design features and characteristics of new materials are given. The major advantage is a primary converter in passive form. Many Western and Soviet patents are reviewed.

OCT type: Multiple

Power systems relevance: $* *$ 
[3] Afanas'ev, V.V., Zubkov, V.P., and Krastina, A.D.,

"Optico-Electronic Current Transformers,"

Elektrichestvo, Vol. 7, pp. 18-24, 1970.

Abstract:

Forcefully argues the case for changing over from conventional current transformers for measuring current in $750 \mathrm{kV}$ systems to opto-electronic designs. Compares the prospects for external amplitude modulation based on the Faraday effect with the prospects for internal pulse-frequency modulation. Considerable attention is paid to the question of analog and digital representation of information for the latter type of design.

OCT type: $\quad$ Multiple

Power systems relevance: ***

[4] Aguet, M., Blech, P., and Ianovici, M.,

"Electro-Optical Current Transformers,"

Bulletin de l'Association Suisse des Electriciens, Vol. 71, No.17, pp. 937-940, September 6, 1980.

Abstract:

Describes experiments and prototype tests on two electro-optical methods. The first (passive) method, briefly described, was abandoned for lack of accuracy; the second, which requires an energy supply, uses a conventional current transformer with minimal insulation. The measured voltage is then converted to a luminous signal which is transmitted to the receptor via an optical fibre. The various elements of the chain are described.

OCT type: Hybrid 
[5] Andresciani, V. and De Leo, R.,

"Current Measurement by a He-Ne Laser in EHV Transmission Lines,"

Elettrotecnica, Vol. 58, No. 11, pp. 607-612, November, 1971.

Abstract:

The Faraday effect may be applied to high current measurements on EHV lines, instead of conventional current transformers. An experimental apparatus which measures currents in the range $0.3 \mathrm{kA}$ to $7 \mathrm{kA}$ is described. The equipment used are heavy flint glasses and conventional optical waveguides. In particular it is shown that optical fibers allow the realization of telemetry and telecontrol systems of high sensitivity and reliability.

OCT type: Bulk glass

Power systems relevance: $* *$

[6] Aritian, A., Ibrahmim, M., Meilopoulos, S., and Zelingher, S.,

"Optic Technology Monitors HV Bus,"

Transmission and Distribution World, pp. 62-68, May, 1997.

Abstract:

Voltage and current optic technology demonstrated at $345 \mathrm{kV}$ substation.

OCT type: Bulk glass

Power systems relevance: $\quad * * *$ 
[7] ArceDiego J.L., Lopez-Ruisanchez, R., Lopez-Higuera, J.M..and Muriel,M.A., "Model of an Openable Faraday-Effect Hybrid-Current Optical Transducer Based on a Square-Shaped Structure with Internal Mirror,"

Applied Optics, Vol. 36, No. 25, pp. 6242-6245, September, 1997.

Abstract:

A new type of clamp-on magneto-optical current transducer based on the Faraday effect is presented. It is openable, hybrid, and square-shaped, and it has an internal mirror that allows the current sensitivity to improve and the effects of the optical activity and temperature-dependent linear birefringence to be rejected. The design and the simulated behavior of the proposed device are described and compared with the conventional (no mirror) transducer.

OCT type: $\quad$ Clamp-on, Bulk glass

Power systems relevance:

[8] Aumont, P. and Pelletier, E.,

"Magneto-Optical Current Transformers Operating with Faraday's Effect"

Revue Generale de l'Electricite, Vol. 80, No. 7-8, pp. 617-622, July-August, 1971.

Abstract:

Reports the latest research and development work of magneto-optical a-c current transformer operating with Faraday's effect, intended for voltage systems over $1000 \mathrm{kV}$. Two models developed further to these studies are described.

OCT type: $\quad$ Multiple

Power systems relevance: ** 
[9] Aumont, P. and Ricard, L.,

"A Current Reducer for Measurements at Very High Voltage,"

MESUCORA International Conference 1973 Sessions 1-3, pp. 14-22, April 12-18, 1973.

Abstract:

The Faraday Effect, whereby the plane of polarization of a light beam is rotated under the influence of a magnetic field, is studied in detail in this paper. It is shown that the measurement of the rotation of the plane of polarisation will give a measure of the magnetic field strength and thereby, the current. Theoretical consideration is given to a number of possible practical applications and it is considered that the use of current reducers based on the magneto-optic technique will find wide application to future voltage networks exceeding $750 \mathrm{kV}$. Schematic diagrams are given for two possible applications of the optical reducer.

OCT type: $\quad$ Multiple

Power systems relevance: $* *$ 
[10] Bargmann, W.-D. and Winterhoff, H.,

"Method of Current Measurement in High-Voltage Systems (Faraday Effect in Optical Waveguides),"

Wissenschaftliche Berichte AEG-Telefunken, Vol. 55, No. 1-2, pp. 123-130, 1982, German.

Abstract:

Isolation and saturation problems as well as bandwidth limitation are considerably reduced by this method. The use of optical fibers involves physical problems such as the double refraction and the dependence on temperature of the circular double refraction. Since the Verdet constant remains sufficiently high even in the wavelength range of the GaAlAs laser, this laser which is characterized by long life and good linear polarization, may be employed as radiation source. In a test assembly comparative measurements were performed with a conventional current transformer in the range from $1000 \mathrm{~A}$ to $6000 \mathrm{~A}$.

OCT type: $\quad$ Bulk glass

Power systems relevance: * 
[11] Beatty, J., Meyer, T.J., and Ulmer, E.A.,

"Application and Field Trial of a High Accuracy Optical Current Transducer for Electrical Power Systems,"

EPRI: Optical Sensing in Utility Applications, San Francisco, USA, May 14-15, 1991.

Abstract:

This paper reports the results of a year long joint Florida Power \& Light (FPL) / Square D Company field trial at FPL's Manatee Power Plant Switchyard of a new high accuracy Optical Current Transducer (OCT) system. The system measures electric phase currents flowing through a high voltage $230 \mathrm{kV}$ substation transmission line terminal. The test is being conducted for demonstrations of utility metering and current relaying applications of the Optical Current Transducer.

The Optical Current Transducer utilizes the Faraday Effect optical technique and its performance was monitored over a range of field operating temperatures, current levels and other influences.

Optical Current Transducer performance is referenced to an oil-filled, combination Current Transformer (CT) and Voltage Transformer (VT) that was installed in series with the new Optical Current Transducer. Outputs from an Optical Current Transducer compatible solid state watthour meter were compared to a conventional solid state watthour meter fed by the oil-filled Current Transformer. The Voltage Transformer (VT) is connected to both systems.

Basic Optical Current Transducer benefits, characteristics and typical laboratory measurement results are included. Development of project objectives from utility and manufacturer view points, field test configurations. Optical Current Transducer installation and maintenance experience are reported. Variations in the Optical Current Transducer output with respect to the Current Transformer output overtime, temperature and primary current levels were determined. Discussions of actual field problems in installation, automated test data collection, sensor temperature dependence, and electronics noise susceptibility are provided using the results to date. Future OCT plans and the expected impact of this device for future utility applications are also briefly explored.

The overall Optical Current Transducer metering accuracy was $+/-0.2 \%$ over a $200 \mathrm{~A}$ to $1400 \mathrm{~A}$ current range and $0^{\circ} \mathrm{C}$ to $40^{\circ} \mathrm{C}$ temperature range. The output offset error was $-0.4 \%$ and peak error deviations were within $+/-0.6 \%$ of the reference standard.

OCT type: Bulk glass

POWER SYSTEM RELEVANCE: **** 
[12] Ben-Kish, A., Konforti, N., Tur, M., and Hafir, E.,

"Design, Construction and Characterization of a Portable Fiber-Optic Current Sensor,"

7th Optical Fibre Sensors Conference, pp. 97-100, Sydney, Australia, December 2-6, 1990.

Abstract:

A new compact design has resulted in an all-dielectric Faraday-effect fiber current sensor that is stable, rugged and portable. Using a 3-turn, $150 \mathrm{~mm}$ loop, the device features a noise equivalent current of $0.23 \mathrm{~A} / \mathrm{Hz}^{1 / 2}$ and an unambiguous dynamic range of $56 \mathrm{~dB} / \mathrm{BW}^{1 / 2}$. Bandwidth, currently at $380 \mathrm{kHz}$ can be tailored to specific needs. The role of bending-induced-birefringence in limiting the scale factor has been extensively studied, both theoretically and experimentally.

OCT type: Fiber

Power systems relevance: *

[13] Ben-Kish, A. and Tur, M.,

"Geometrical Separation Between the Birefringence Components in Faraday-Rotation Fiber-Optic Current Sensors,"

Optical Letters., Vol. 16, No. 9, pp. 687-689, May, 1991.

Abstract:

A novel optical fiber current sensor for low-current measurements is proposed and tested. By winding a commonly used low-birefringence single-mode optical fiber in a special geometry, one can circumvent the bend-induced birefringence problem. Smaller sensors can now be built with a sensitivity that linearly increases with the number of fiber windings.

OCT type: Fiber

Power systems relevance: ** 
[14] Bigelow, R., Sadler, J., Stapleton, T., Sun, M. and Wickersheim, K., "Fiber-Optic Sensing for Electric Power Transmission,"

Proceedings: EPRI 1992 Workshop on Optical Sensing In Utility Applications, pp. 11.1-11.2, 1992.

Abstract: None

OCT type: Fiber

Power systems relevance: *

[15] Blake, J.N., Tantaswadi, P.T., and DeCarvalho, R.T. ,

"All-Fiber in-Line Sagnac Interferometer Current Sensor,"

SPIE Proc., The Intl. Society for Optical Engineering, Vol. 2622, pp. 315-319, May, 1995.

Abstract:None

OCT type: $\quad$ Fiber

Power systems relevance: * 
[16] Blake J., Tantaswadi, P., and DeCarvalho, R.T.

"In-line Sagnac Interferometer Current Sensor,"

IEEE Transactions on Power Delivery, Vol.11, No. 1, pp. 116-121, January, 1996.

Abstract:

We demonstrate for the first time a near shot noise limited in-line Sagnac interferometer current sensor. It is shown to have a number of advantages over the optical current sensors based on polarimetric Faraday and Faraday/Sagnac loop interferometer topologies, including lower sensitivity to environmental disturbances, less demanding optical components, and easy installation.

OCT type: $\quad$ Fiber

Power systems relevance: $* *$

[17] Bohnert, K., Brandle, H. and Frosio, G.,

"Field Test of Interferometric Optical Fiber High-Voltage and Current Sensors,"

Proceedings of the Tenth International Conference on Optical Fibre Sensors, pp. 16-19, 1994.

Abstract:

Optical fiber sensors are of considerable interest to the electric power industry. Predictably attractive features as compared to conventional instrument transformers include the inherent galvanic isolation of the sensor head from ground potential, less sensitivity to electromagnetic interference, smaller size, and higher safety. Here we report on an ongoing field test of interferometric current and voltage sensors which have been integrated into the gas-insulated high voltage switchgear (GIS) of a $220 \mathrm{kV}$ high-voltage switching station. The voltage sensor exploits the converse piezoelectric effect in quartz. The piezoelectric deformation of several crystals induced by the applied voltage is transduced to a dual-mode sensor fiber which is remotely interrogated by using "white light" interferometry. The current sensor makes use of the Faraday effect in appropriately modified commercial fiber gyroscope. The test is to determine the long-term performance of the sensors under field conditions with adverse environmental effects.

OCT type: $\quad$ Fiber

Power systems relevance: $* * *$ 
[18] Bombi, F., Bono, R. Clemente, G. and Rea, M.,

"An Optical Transmission and Incrementally Coded Current Reducer,"

Rendiconti della Riunione Annuale dell' Associazione Elettrotecnica Italiana, Vol. 49, No. 3, pp B37/1-8, 1974, Italian.

Abstract:

For the short-circuit protection of high voltage lines equipped with $\mathrm{SF}_{6}$ insulated sub-stations, there exists a problem of current measurement for control purposes. Systems involving the modulation of a polarized light wave (Faraday effect) by the magnetic field of the line current, or the coding of the current signal and conversion to an optical signal by means of emitter diodes or solid state lasers, and the use of optical fiber transmission of such signals, are described.

OCT type: $\quad$ Multiple

Power systems relevance: *

[19] Bosselmann, T.,

"Comparison of 4 Different Optical Fibre Coil Concepts for High Voltage Magneto-optic Current Transformers,"

9th International Optical Fiber Sensors Conference, Florence, Italy, 1993.

Abstract:

According to the four most promising concepts, fiber-optic current sensor sample coils were made. The performance of these fiber coils is compared concerning residual linear birefringence, current sensitivity, scale factor, temperature and vibration sensitivity.

OCT type: Fiber

Power systems relevance: $* *$ 
[20] Bosselmann, Y.T. and Menke, P.,

"Intrinsic Temperature Compensation of Magneto-optic AC Current Transformers with Glass Ring Sensor Head,"

Tenth International Conference on Optical Fibre Sensors, pp. 20-23, 1994.

Abstract:

Magnetooptic current sensors are gaining interest due to the following advantages: simple potential separation, immunity against electromagnetic interference, high dynamic range and bandwidth and compact design. Magnetooptic current transformers - MOCT - offer a complete separation of energy and signal distribution in power industry. Cross sensitivities against temperature and vibrations however limit severely the practical application of such MOCTs. The temperature dependence of the current sensitivity can be corrected by means of an external temperature measurement at the sensor head. This method increases the sensor complexity and cost. In the following anmtrinsic compensation is presented which avoids these disadvantages. The intrinsic temperature measurement by an intelligent signal analysis and correction increases the accuracy of a MOCT to a practically necessary value of below $0.5 \%$. Additionally it provides information about the temperature of the sensor head.

OCT type: Bulk glass

Power systems relevance: * 
[21] Bosselmann, T.,

"Electric and Magnetic Field Sensing for High Voltage Applications,"

SPIE Proceedings Vol. 3097: Optical Fiber Sensors Technologies and Applications, Munich, Germany, 1997.

Abstract:

Electric and magnetic fields can be measured optically, either directly via Pockels and Faraday effect or indirectly via Piezo effect. In high voltage applications fiber-optic sensors are especially attractive for their ability of easy potential separation. For electric fields the Pockels effect in BSO, BGO crystals is mostly read out polarimetrically. The current is mostly measured via the Faraday effect in fibers or bulk optics polarimetrically, but also by means of a Sagnac interferometer. Electro-optic voltage and magneto-optic current sensors have quite a mature state of development and show their benefits in a lot of field tests and installation in high voltage switchgears.

OCT type: $\quad$ Multiple

Power systems relevance: $* * *$ 
[22] Bosselmann, T.,

"Magneto- and Electrooptic Transformers Meet Expectations of Power Industry,"

12th International Conference on Optical Fiber Sensors, Williamsburg, USA, October 28-31, 1997.

Abstract:

In the field of power industry enormous energies are transmitted. A complete separation of energy and measuring signal channel for current and voltage is advantageous but cannot be obtained by electrical sensors as inductive, resistive and capacitive of current and voltage transformers. This leads to an expensive and costly amount insulation. Any across stock can cause expensive damage to a switch yard. The benefits of optical transformers for current and voltage as complete channel separation, cost and size reduction have to be paid for by cross sensitivities not known to the electric transformers: a twofold cross sensitivity to temperature and vibration. Smith from CERL made the first field demonstrations of current measurements with $2 \%$ accuracy at a $500 \mathrm{MW}$ generating station in 1979. Papp and Harms from Siemens presented a free standing optical transformer with a class accuracy of $0.2 \%$ at room temperature which decreased slightly to $0.5 \%$ in a range from $-25^{\circ} \mathrm{C}$ to $+45^{\circ} \mathrm{C}$ in 1980 . Since then a lot of different concepts have been investigated, field tests have been performed to mature the optical technologies involved. Today the optical transformers have proven the technical feasibility of measuring for electric power tasks. Future development is orientated to improving the performance and to optimizing the manufacturing process. It should not be omitted that a considerable effort is still needed to convince the in general conservative customers of this new technology. In the following we will look at the development of optical current transformers starting with practical considerations of the Faraday effect and ending with the description of the development up to now. The development of voltage sensors will be described analogously. As the basic effects have been described already extensively, the focus will be on the industrial development.

OCT type: $\quad$ Multiple

Power systems relevance: *** 
[23] Brown, F.,

"Optical Current Transformers for $69 \mathrm{kV}$ Underground Cable Protection,"

EPRI: Optical Sensors for Utility T\&D Applications, Portland, Oregon, July 20-21, 1995.

Abstract:None

OCT type: Bulk glass

Power systems relevance: ****

[24] Bush, S.P, and Jackson, D.A.,

"Dual-Channel Faraday Current Sensor Capable of Simultaneous Measurement of 2 Independent Currents,"

Optics Letters, Vol. 16, No. 12, June 15, 1991.

Abstract:None

OCT type: Bulk glass

Power systems relevance: * 
[25] Bush, S.P. and Jackson, D.A.,

"Numerical Investigation of the Effects of Birefringence and Total Internal-Reflection on Faraday-Effect Current Sensors,"

Applied Optics, Vol. 31, No. 25, pp. 5366-5374, September 1, 1992.

\section{Abstract:}

The effects of birefringence and total internal reflection on the performance of current sensors that use the Faraday effect have been modeled numerically. The results show that, when these effects are present, the output electric field azimuth is affected by the position of the current-carrying conductor. In sensors that use highly circular birefringent fibers, however, the output azimuth is not affected.

OCT type: Multiple

Power systems relevance: *

[26] Buyno, A. and Lukaszczyk, M.,

"Magneto-optical Method of Alternating Current Measurement,"

Wiadomosci Elektrotechniczne, Vol. 48, No.12, pp. 317-319, June 15, 1980, Polish.

Abstract:

Optical methods used in high voltage metrology are presented along with the principal advantages of these methods. Physical fundamentals of methods using Faraday's magneto-optical effect are given. The construction of non-conventional alternating current transformers designed to operate in highest tension power lines, is described. The construction of a magneto-optical modulator developed at the High-Voltages Institute of the Warsaw Technical University, is presented.

OCT type: $\quad$ Multiple

Power systems relevance: ** 
"Transformateur de Courant Magneto-Optique a Effet Faraday, Astatique.,"

RGE, Revue Generale de l'Electricite, Vol. 80, No. 11, pp. 815-826, November, 1971, French.

Abstract:

The authors give the results of their experiments and tests on a model of current transformer using the Faraday effect. The astatism obtained by means of two magneto-optic channels makes the equipment insensible to external magnetic fields. An actual model, designed for voltage of $750 \mathrm{kV}$ was tested and showed a $0.5 \%$ accuracy.

OCT type: Bulk glass

Power systems relevance: * *

[28] Carome, E.F. and Stumpf-Carome, J.M.,

"Fiberoptic Vibration and Electric Current Sensors: Encounters with the Electric Power Industry,"

EPRI: Optical Sensing in Utility Applications, Philadelphia, USA, August 25-26, 1992.

Abstract:

Edjewise Sensor Products, Inc. (ESP) set out approximately three years ago to produce versatile, relatively simple and lower cost sensor systems that possesses all of the advantages of fiberoptic devices for power industry applications. Discussed in this paper is an accelerometer, i.e., a vibration sensor that may be used to monitor generator and transformer vibrations. Also discussed in some detail is a current sensor that may be used for fault detection and other applications requiring lower than metering accuracies Highlighted is the use of these sensors to detect faults on the $138 \mathrm{kV}$ supply lines of a new distribution substation in Cleveland, Ohio. Finally, some of ESP's experiences introducing these devices to the power industry are presented.

OCT type: $\quad$ Piezo-electric

Power systems relevance: $* * * *$ 
[29] Caton, W. and Katzenstein, J.,

"Absolute Electric Current Probe Based on the Faraday Effect,"

Journal of Research of the National Bureau of Standards, Vol. 89, No. 3, pp. 265-276, May-June, 1984.

Abstract:

OCT type:

Power systems relevance: 
[30] Cease, T.W., Driggans, J.G., and Weikel, S.J.,

"Optical Voltage and Current Sensors used in a Revenue Metering System,"

IEEE Transactions on Power Delivery, Vol. 6, No. 4, pp. 1374-1379, 1991.

Abstract:

The authors discuss the development of an optical voltage sensor as part of an all optical sensor based revenue metering system. The magneto-optic or Faraday effect was used to implement a magneto-optic voltage transducer (MOVT) to measure voltage by sensing the current flow through a capacitor connected from a $161 \mathrm{kV}$ transmission line to ground. The current sensor was a magnetooptic current transducer (MOCT) developed previously. The design of the voltage sensors using the magneto-optic effect allows the implementation of a revenue metering system using all optical sensors. This method of measuring voltage was previously unproven. The components of the all optical sensor revenue metering system, the site installation, and the data acquisition system used to monitor the system are described. Decisions leading to the design of the MOVT are discussed.

OCT type: Bulk glass

Power systems relevance: $* * *$

[31] Cease, T.W. , and Johnston, P.M.,

"A Magneto-optic Current Transducer,"

IEEE Transactions on Power Delivery, pp. 548-555, Long Beach, USA, July 9-14, 1989.

Abstract:

A current measurement technique using the magneto-optic or Faraday effect, has been developed, tested, and demonstrated. The device developed is a magneto-optic current transducer (MOCT). It uses the rotation of the plane of polarization by a magnetic field exhibited in certain glasses (Faraday effect). Test data obtained in an extensive field evaluation of the MOCT were compared with the design qualification data gathered during the development phase of this project. The analysis indicates that operation of the MOCT-based metering system under field conditions compares favorably with performance predicted during design qualification.

OCT type: Bulk glass

Power systems relevance: $* * *$ 
[32] Cernosek, R.W.,

"High Frequency Response of Fiber Current Sensors with Noncircular and Nonconcentrated coils,"

8th Optical Fiber Sensors Conference, pp. 398-401, Monterey, USA, January 29-31,1991.

Abstract:

The frequency response of the Faraday rotation in fiber current sensors is computed and measured for sensor coils of noncircular cross section and with displaced coil and conductor axes. Resonances are observed at higher frequencies with magnitudes approaching that of the low frequency response. Narrowband current sensors at frequencies above $100 \mathrm{MHz}$ are reported.

OCT type: Fiber

Power systems relevance: *

[33] Chatrefou, D.,

"Application of Optical Sensors to EHV Substations,"

EPRI: Optical Sensors for Utility T\&D Applications, Portland, Oregon, July 20-21, 1995.

Abstract:None

OCT type: Bulk glass

Power systems relevance: **** 
[34] Chatrefou, D. and Meyrueix, P., "Faraday Effect Current Sensor, Design of a Prototype,"

The Role of Optical Sensors and Power Systems Voltage and Current Measurements, NBS Workshop, Gaithersburg, USA, September 16-18, 1987.

Abstract:

A Faraday optical current sensor has been under investigation for several years at GIERS. The solution which has been chosen utilizes a monomode optical fiber for the sensitive element. This sensor has been integrated in a $400 \mathrm{kV}$ porcelain insulator [1]. The good results obtained during studies made at the L.E.P. laboratories in the EdF Renardieres Research Center, will permit us to define a second prototype with respect to the EdF specifications.

OCT type: $\quad$ Fiber

Power systems relevance: $* * *$

[35] Chan, M. and Demokan, M.S.,

"On-Line Fault Location System for Overhead Power Transmission Lines Using Passive Quasi-Distributed Fibre Optic Sensing,"

2nd International Conference on Advances in Power System Control, Operation and

Management, 1993.

\section{Abstract:}

The design of an on-line fault location system for overhead high voltage transmission lines is described, The system utilizes a novel polarimetric fiber-optic current sensing configuration based on the Faraday rotation effect. The fiber-optic sensor detects the current (and its location) induced in the groundwire in the event of a fault. The proposed sensor incorporates a long conventional transmission fiber without compromising the accuracy of measurement as a result of sensitivity to linear birefringence. Its sensing part is all-fiber and is free of polarization sensitive components. The sensing is quasi-distributed, which avoids the necessity for a separate power supply. Thus, the proposed configuration is especially suitable for remote fault location.

\section{OCT type: $\quad$ Fiber}

Power systems relevance: * * 
[36] Christensen, L.H. and Petersen, A.E.,

"Field Test of Optical Voltage and Current Instrument Transformers for Detection of Harmonics," EPRI: Optical Sensors for Utility T\&D Applications, Portland, Oregon, July 20-21, 1995.

Abstract:

Over the last decade the Power Engineering Department at the Technical University of Denmark has performed research within the field of optical sensors for T\&D applications. Earlier papers describing these efforts have been presented in San Francisco and Philadelphia. Recently two of the Ph.D. students at the department have presented their designs of an optical voltage transformer and an optical current transformer respectively, both for use in the $132 \mathrm{kV}$ system. These two transformers have now been subject to a field test. The transformers have been installed in an $400 \mathrm{kV} / 132 \mathrm{kV}$ transformer station for 6 weeks during January and February 1995. The aim of the field test was to test the designs under real conditions including frost and snow. Furthermore, the transformers were part of a program concerning the measurement of voltage and current harmonics on the $132 \mathrm{kV}$ transmission lines. As one of the advantages of the optical transformers is the high bandwidth it was decided to compare the measurements with simultaneously recorded data obtained from conventional instrument transformers. The principles of the employed optical transformers are briefly introduced. Measuring data is presented that compares data from the optical transformers with data from the conventional instrument transformers. The attention is focused on the content of harmonics in the measurement signals. During the tests a mechanical vibration problem in the design of the voltage transformer was detected which would not have been found otherwise.

OCT type: Magnetic concentrator

Power systems relevance: $* * *$ 
[37] Chu, W., Haldar, D. McStay, D. and Rogers, A.J.,

"Interference of the Faraday Coupled Signal with the Residual Mode Component in a Highly-Birefringent Optical-Fibre Current Sensor,"

8th Optical Fibre Sensors Conference, pp. 165-168, Monterey, USA, January 29-31, 1992.

\section{Abstract:}

Highly linear-birefringent $(\mathrm{HiBi})$ optical fibers have been widely used to transmit linearly polarised light in various applications because of their polarization-holding properties. Faraday coupling in linear-birefringent fibers have been reported previously. Recently, an optical fiber current sensor which makes use of the Faraday Effect to couple light resonantly from one mode to an originally-empty mode of a $\mathrm{HiBi}$ fiber, when the fiber is subjected to a periodic magnetic field, has been reported. In this paper we report that the resonance of Faraday coupling is dependent on the relative axial position of the fiber and the magnetic field. This is caused by the interference of the Faraday coupled signal and the residual empty mode component, due to imperfect launching of purely linearly polarized light into one eigenmode of a HiBi fiber. A good understanding of this dependence will be essential to the design of the HiBi fiber current sensor. The HiBi current sensor reported to date has used a periodic conductor array (PCA) to generate the required periodic magnetic field. In a practical environment, the required periodicity may be effected by periodically doping the fiber with materials which can either enhance or shield the magnetic field acting on the fiber. An initial result of Faraday coupling in a magnetically-shielded $\mathrm{HiBi}$ fibre using ferrite beads will be presented here.

OCT type: Fiber

Power systems relevance: *

[38] Chu, W., McStay, D. and Rogers, A.J.,

"Current Sensing by Mode Coupling in Fibre via the Faraday Effect,"

Electronic Letters, Vol, 27, No. 3, pp. 207-208, January, 1991.

Abstract:

A new class of optical-fiber current sensor which uses periodic Faraday coupling in a highly birefringent optical fiber is described. The coupling was found to be strongly dependent upon the periodic field spacing, the wavelength of the light used and the applied magnetic field.

OCT type: Fiber

Power systems relevance: * 
[39] CHU, B.C.B., NING, Y.N., and JACKSON, D.A.,

"Faraday Current Sensor That Uses a Triangular-Shaped Bulk-optic Sensing Element,"

Optics Letters, pp. 1167-1169, Vol. 17, No. 16, August 15, 1992.

Abstract:

OCT type: Bulk Glass

Power systems relevance: *

[40] Chu, B.C.B., Ning, Y.N. and Jackson, D.A.,

"An Optical Current Comparator,"

Measurement Science \& Technology, Vol 4, No. 11, pp. 1187-1193, November 1993.

Abstract:

The design and performance of an optical current comparator based upon a triangular shaped bulk glass sensing element are presented. The effect of the Faraday rotation produced in the sensing element by an unknown large current is nulled by a smaller known current of opposite polarity, thus giving an absolute measurement of the unknown current. The design requirements of the sensor configuration are analyzed theoretically by computer simulation and tested experimentally for both ideal and non-ideal sensors. The sensors have many applications in the power distribution industry, as both absolute and differential AC and DC measurements up to very high currents are possible.

OCT type: Bulk glass

Power systems relevance: * 
[41] Chu, B.C.B., Ning, Y.N. and Jackson, D.A.,

"An Optical Current Comparator for Absolute Current Measurement,"

Sensors and Actuators A-Physical, Vol. 37, No. 8, pp. 6, June-August, 1993.

Abstract:

The design and performance of an optical current comparator based upon a triangular-shaped bulk glass sensing element are presented. The effect of the Faraday rotation produced in the sensing element by an unknown large current is nulled by a smaller known current of opposite polarity, thus giving an absolute measurement of the unknown current. The design requirements of the sensor configuration are analyzed theoretically by computer simulation and tested experimentally for both ideal and non-ideal sensors. The sensor may have many applications in the power distribution industry, as both absolute and differential ac and dc measurements up to very high currents are possible.

OCT type: Bulk glass

Power systems relevance: *

[42] Clarke, I.G.,

"Temperature-Stable Spun Elliptical-Core Optical-Fiber Current Transducer," Optics Letters, Vol 18, No. 2, pp. 158-160, January, 1993.

Abstract:

A temperature-stable electrical current transducer, with a spun birefringent elliptical-core optical fiber, has been designed, theoretically analyzed, constructed, and tested. The transducer uses a novel form of Sagnac interferometer to cancel the temperature dependence of the spun fiber.

OCT type: $\quad$ Fiber

Power systems relevance: *

[43] Clarke, I.G., Geake, D., Bassett, I.M., Poole, S.P., and Stokes, A.D., "A Current Sensor Using Spun Birefringent Fibre in a Sagnac Configuration," $9^{\text {th }}$ International Optical Fiber Sensors Conference, 1993.

Abstract:None

OCT type: $\quad$ Fiber

Power systems relevance: * 
[44] Clarke, L.G., Rochford, K.B., Rose, A.H., and Day, G.W., "A Polarization Insensitive 3x3 Sagnac Current Sensor Using Polarizing Spun High-Birefringence Fiber,"

$10^{\text {th }}$ International Conference on Optical Fibre Sensors, SPIE; Vol. 2360, 1994.

Abstract:

The response functions of previously reported $3 \times 3$ Sagnac current sensors are strongly dependent on input polarization, so systems require careful control of the input polarization state. In this paper, we describe a simple method for eliminating this polarization dependence so that stable response functions are obtained. We demonstrate the existence of a wavelength range over which spun high-birefringence fiber guides only one elliptically polarized mode, thus preserving a single polarization state. Using this effect, we show that $3 \times 3$ Sagnac current sensor response functions can exhibit stable phase offsets with little sensitivity to input polarization. This provides practical current sensing without the need for polarization control.

OCT type: Fiber

Power systems relevance: *

[45] Cocco, L.,

Phase-Modulated Fiber-Optic Current Transformer/Voltage Transformer, EPRI EL-7421, Project WO4212, July, 1991.

Abstract:

Fiber-optic systems have been identified as a potential means to improve current and voltage monitoring systems for aerial and underground electrical distribution lines. Laboratory samples of fiber-optic current and voltage sensors have been built and tested, and means have been designed to install them on distribution lines.

OCT type: Fiber

Power systems relevance: *** 
[46] Cruden, A., Richardson, Z.J., McDonald, J.R., and Andonvic, I.,

"Compact 132 kV Combined Optical Voltage and Current Measurement System,"

IEEE Instrumentation and Measurement Technology Conference, Ottawa, Canada, May 19-21, 1997.

Abstract:

This paper presents details of a compact $132 \mathrm{kV}$ insulator arrangement developed for use with unlinked optical voltage and current transducers (OCT and OVT). The measured temperature characteristics of terbium gallium garnet, the Faraday rotator in the OCT, is given and compared to previously published results. The application of this data to a temperature compensation system for the OCT is discussed. In addition, research results associated with the identification of piezoelectric resonance in the OVT is presented and a solution proposed and tested.

OCT type: Bulk glass

Power systems relevance: $* * *$

[47] Cyraniak, A. and Cyraniak, M., "Optoelectronic Current Transformer," Energetyka, Vol. 30, No. 1, pp. 19-21, January, 1976, Polish.

Abstract:

Discusses the design and properties of an optoelectronic transformer for current measurements in EHV stations, based on the magneto-optical Faraday effect. The advantages gained by replacement of conventional current transformers with optoelectronic ones are mentioned.

OCT type: $\quad$ Multiple

Power systems relevance: $* *$ 
[48] Dandridge, A., Tveten, A.B., and Giallorenzi, T.G., "Interferometric Current Sensors Using Optical Fibres,"

Electronics Letters, Vol. 17, No. 15, pp. 523-525, July, 1981.

Abstract:

Two types of fiber-optic current sensor have been developed and successfully tested in the laboratory (magnetostrictive jacketing materials and a heating effect) to produce a phase shift in the optical fiber. A ruggedized all-fiber interferometer powered by a diode laser was used to detect the phase changes induced by the electrical current.

OCT type: $\quad$ Fiber (non-Faraday effect)

Power systems relevance: *

[49] Dawson, J. W., MacDougall, T. W., and Hernandez, E.,

"Verdet Constant Limited Temperature Response of a Fiber-Optic Current Sensor,"

IEEE Photonics Technology Letters, Vol. 7, No. 12, December, 1995.

Abstract:

A novel all-fiber, magnetooptic current transformer is reported. Changes of the optical system response to current with temperature have been measured to be linear with a slope of $6.9 \times 10^{-5} /{ }^{\circ} \mathrm{C}$ with an error bar of less than $0.2 \%$ over the temperature range of $-40{ }^{\circ} \mathrm{C}$ to +80 ${ }^{\circ} \mathrm{C}$. This temperature dependence can be entirely attributed to the change in the Verdet constant of the glass. This is, to our knowledge, is the first report of a birefringence free fiber-optic current sensor with Verdet constant limited performance. The sensor's response to current is linear to within $0.3 \%$ from less than $1 \mathrm{~A}$ up to $100 \mathrm{~A}$, the limit of our measurement capability.

OCT type: $\quad$ Fiber

Power systems relevance: * 
[50] Day, G..W. and Etzel, S.M.,

"Annealing of Bend-Induced Birefringence in Fiber Current Sensors,"

International Conference on Integrated Optics, Venice, Italy, 1985.

Abstract:

The bend-induced linear birefringence in coils of single mode optical fiber has been greatly reduced by annealing. This should allow the construction of electric current sensors that are much more compact and potentially more sensitive than previously possible.

OCT type: $\quad$ Fiber

Power systems relevance: * 
[51] Day, G.W., Hale, P.D., Deeter, M., Milner, T.E., Conrad, D. and Etzel, S.M., Limits to the Precision of Electro-Optic and Magneto-Optic Sensors, NBS Technical Note 1307, March, 1987.

Abstract:None

OCT type: $\quad$ Multiple

Power systems relevance: *

[52] Day, G.W.,

"Optical Power Line Voltage and Current Measurement Systems: Volume I, Limits to the Precision of Electro-Optic and Magneto-Optic Sensors"

EPRI Report EL5431, Palo Alto, 1987.

Abstract:

This study began with a central question, "What precision can be achieved with an electro-optic sensor or a magneto-optic current sensor." The answer has been pursued in numerous ways through an investigation of the basic properties of materials and components (both as reported in the literature and new data generated in our laboratory), through attempts to demonstrate the feasibility of overcoming certain limitations in the properties of components, through analysis of some fundamental limitations, through the proposal of new or refined designs, and through discussions with numerous other investigators. It was concluded that ease of obtaining high precision (in a context) is not included among the advantages of using optical sensors for measurement of electromagnetic quantities. The principal difficulty was that sensors have to maintain their calibration over broad temperature ranges (at least $100^{\circ} \mathrm{C}$ ) without the possibility of temperature stabilization. Specifically, using relatively standard approaches and an appropriate definition of precision, a precision not better than about $\pm 1 \%$ can be expected. Achieving this level of precision will require wise choices of materials, components, and design; numerous suggestions are offered.

OCT type: $\quad$ Multiple

Power systems relevance: * 
[53] Day, G.W., Deeter, M.N., Rose, A.H., and Rochford, K.B.,

"Recent Advances in Faraday Effect Sensors,"

Springer Proceedings in Physics: Optical Fiber Sensors, Vol. 44, pp. 250-254, 1989.

Abstract:

This paper reviews recent developments in the application of Faraday effects to electric current and magnetic field sensing.

OCT type: Multiple

Power systems relevance: *

[54] Day, G.W., Deeter, M.N., Rose, A.H., and Rochford, K.B., "Faraday Effect Sensors for Magnetic Field and Electric Current," SPIE Interferometry '94 May, 1994.

Abstract:

Recent research at NIST has greatly extended the capabilities of Faraday effect sensors for both magnetic field and electric current measurements. Current sensors using single-mode optical fiber show temperature stability near material limits, and are approaching commercial availability for applications in the power industry. The Faraday effect in iron garnets shows great promise for measuring current at low levels and/or high speeds. Sensors with noise equivalent currents of about $200 \mathrm{nA} / \mathrm{Hz}^{1 / 2}$ have been demonstrated. Magnetic field sensors using iron garnets and flux concentration, have led to sensors with noise equivalent magnetic fields in the range of 1 $\mathrm{pT} / \mathrm{Hz}^{1 / 2}$.

OCT type: Multiple

Power systems relevance: * 
[55] Day, G.W., Rochford, K.B., and Rose, A.H., "Fundamentals and Problems of Fiber Current Sensors,"

$11^{\text {th }}$ International conference on Optical Fiber Sensors, Sapporo, Japan, May 21-24,1996

Abstract:

This paper briefly reviews the history and present commercial status of optical fiber sensors, and then summarizes recent research aimed at improved performance, lower cost, and wider areas of application.

OCT type: Fiber

Power systems relevance: $* *$

[56] Day, G.W. and Rose, A.H.,

"Faraday Effect Sensors: The State of the Art,"

SPIE: Proceedings Fiber Optic and Laser Sensors, SPIE, Vol. 985, pp. 138-150, 1988.

Abstract:

The Faraday effect is becoming widely used as an optical method of measuring electric current or magnetic field. It is particularly advantageous where the measurements must be made at high voltage or in the presence of electromagnetic interference, and where speed or stability are considerations. In this paper we review the development of the technology over the last twenty years, with an emphasis on the basic principles, design considerations, and performance capabilities of sensors that represent the latest achievements. Faraday effect current sensors are now used routinely in the measurement of large current pulses, and are starting to become available for ac current measurements in the power industry. Recent developments include their extension to the measurement of currents in the milliampere range and substantial reductions in size. Similar devices, in slightly different configurations, can be used for magnetic field measurements. Further improvements, based on new fiber types and new materials, are projected.

OCT type: Multiple

Power systems relevance: * 
[57] Dinev, P.D.,

"A Two-Dimensional Remote Fibre-Optic Magnetic Field and Current Sensor,"

Measurement Science \& Technology, Vol. 7, No. 9, pp. 1233-1237, September, 1996.

Abstract:

A new type of a remote two-dimensional magnetic field and current sensor has been developed to measure constant (DC) and variable (AC) magnetic fields and currents simultaneously in two perpendicular directions with a linearity error less than $0.1 \%$. Based on the elastic cantilever principle, the deflection of an aluminium-coated optical fiber due to the Lorentzian force is sensed by an optical lever and a continuous position optical sensor. The sensor shows an extremely wide measurement range, $60 \mathrm{~dB}$ dynamic range, $-45 \mathrm{~dB}$ cross talk and a resolution of 5 $\mu \mathrm{T}$ (for the magnetic flux density) and $0.3 \mathrm{~A}$ (for the current). Due to the separation in space of the registration and the sensing parts, the sensor can be designed to have any desired response or sensitivity and has no upper limits. It is designed mostly to measure strong and extremely strong magnetic flux densities and currents.

OCT type: $\quad$ Fiber (non-Faraday effect)

Power systems relevance: *

[58] Donati, S. and Annovazzi-Lodi, V. and Tambosso, T., "Magneto-Optical Fibre Sensors for Electrical Industry: Analysis of Performances," IEE Proceedings, Vol. 135, No. 5, pp. 372-382, October, 1988.

Abstract:

We present an analysis of all-fiber sensors intended for current and magnetic field measurements in electrical systems. After reviewing magneto-optic effects in connection to application requirements, we calculate the theoretical performances of the sensor, terms of the sensitivity, bandwidth, dynamic range and linearity, both for polarimetric and interferometric readout schemes. Sources of errors in the fiber and optical components are analyzed in their limitations to sensitivity are evaluated. Birefringence control is discussed, and the results applied to develop several linked and unlinked sensor configurations. Finally, experimental data are compared to theoretical values.

OCT type: $\quad$ Fiber

Power systems relevance: $* *$ 
[59] Dutta, P.K., and Duttagupta, P.B.,

"Accurate Sensing of Large Currents Using Optical Fibres in Disturbed Power System

Environment,"

IEE International Conference on Advances in Power System Control, Operation and

Management, November 5, 1991.

Abstract:None

OCT type: $\quad$ Fiber

Power systems relevance: **

[60] Edwards, H. O., Jedrzejewski, K. P., Laming, R. I. and Payne, D. N., "Optimal Design of Optical Fibers for Electric Current Measurement," Applied Optics, Vol. 28, No. 11, pp. 1977-1979, June, 1989.

Abstract:

The current sensitivity and bandwidth of the optical fiber current monitor are analyzed. The optimal sensitivity is proportional to the ratio of fiber attenuation to the Verdet constant and a specific fiber length. A selection of compound glasses has been investigated with a view to improving bandwidth and sensitivity over standard silica-fiber systems. A trial fiber of the most promising glass (Schott F7) has been fabricated and characterized.

OCT type: Fiber

Power systems relevance: *

[61] Emerging Technology Working Group and Fiber Optic Sensors Working Group, "Optical Transducers for Power Systems - A Review,"

IEEE Transactions on Power Delivery, Vol. 9, No. 4, pp 1778-1788, 1994.

Abstract:

The technology of the optical measurement of current is reviewed. Several fundamentally different approaches are described. Implementations from a number of manufacturers are examined so as to highlight the similarities and the differences. Experience with optical current transducers is reported. The question of interfacing to an optical current transducer is discussed. The special problems posed by calibration of this kind of instrument are reviewed.

OCT type: Multiple

Power systems relevance: $* * *$ 
[62] Erickson, D.,

"BPA Experience with Passive and Active Optical Sensors,"

The Role of Optical Sensors and Power Systems Voltage and Current Measurements, NBS

Workshop, Gaithersburg, USA, September 16-18, 1987.

Abstract:

Since the middle 1970's, BPA (Bonneville Power Administration) has been employing the salient features of optical sensors for a wide variety of instrumentation tasks in high power research. While most of the activity has been in the field of active optical sensors using intensity modulation or pulse position modulation with LED's or lasers, BPA started to explore the passive voltage and current measurement concepts as early as 1971. Several initial study projects, using the Pockels and Faraday effects, were undertaken and used at BPA to study fault transients and to explore the potential of using such devices for powerline voltage and current measurements for meter, relay and transient detection (primarily for fault locating) applications.

OCT type: Multiple

Power systems relevance: $* * *$

[63] Erning, L., Yanbing, L., MacAlpine, J.M.K., Benshun, Y., and Zhengying, L., "Development of an Optical Current Measuring System for Power Systems," 10th International Symposium on High Voltage Engineering, August, 1997.

Abstract:

A new optical current measuring system based on the Faraday effect using bulk glass as the sensing element with dual-loop optical path, in which the light is sent back along the nearly same path in the reverse direction using a special designed doubleprism, for high voltage applications has been developed. The influence of birefringence can be partly compensated and the sensitivity of the optical current transducer (OCT) is about 1.5 times higher than the former single-loop OCT due to the nonreciprocity of the Faraday effect. The operating results show that the OCT is satisfactory, with an error less than $\pm 0.2 \% \pm 0.1 \mathrm{~A}$ at room temperature and negligible temperature dependency for currents up to $800 \mathrm{~A}$ in the temperature range from $-15^{\circ} \mathrm{C}$ to $+40^{\circ} \mathrm{C}$.

OCT type: Bulk glass

Power systems relevance: $* *$ 
[64] Esman, R., D., Kersey, A. D., and Marrone, M.J., "Polarization Insensitive Current and Magnetic Field Optic Sensor," Journal of Lightwave Technology, Vol. 13, No. 7, pp. 1378-1384, July, 1995.

Abstract:

OCT type:

Power systems relevance: *

[65] Fang, X. and Claus, R. O.,

"Optimal Design of IRIS-Based Polarimetric Intrinsic Fiber Optic Current Sensors," Journal of Lightwave Technology, Vol. 14, No. 7, pp.1664-1673, July, 1996.

Abstract:

Performance of reciprocity-compensated polarimetric fiber optic current sensors are analyzed for typical will birefringence fibers. The intensity-based reciprocity-insensitive structure (IRIS) can effectively balance the birefringent and lossy influences in intrinsically low-birefringence fiber-based current sensors, while supplementary techniques such as wavelength control and pole-zero cancellation are needed to eliminate the strong polarization-coupling effect in this spun fiber-based sensors. It is shown from simulation that the stability of the sensor can be maximized by using the IRIS and a suitable initial birefringence.

OCT type: $\quad$ Fiber

Power systems relevance: * 
[66] Fang, X., Wang, A., May, R. G., and Claus, R. O.,

"A Reciprocal-compensated Fiber-optic Electric Current Sensor,"

Journal of Lightwave Technology, Vol. 12, No. 10, pp. 1882-1890, October, 1994.

Abstract:

A novel reciprocal-compensated structure is demonstrated for intensity-modulated intrinsic fiber-optic current sensors. Both the component losses and birefringence influences can be partly compensated using this configuration, and the sensor is sensitive only to non-reciprocal Faraday rotation. The dependence of the signal on circular birefringence drift can be reduced by factor better than 10 for low birefringence fibers. The property of total reciprocity reduces this sensitivity of the current sensor to temperature changes in vibrations. The experimental results agree well with the theoretical predictions for the sensor, fabricated using a coil of low birefringence single-mode fiber.

OCT type: $\quad$ Fiber

Power systems relevance: *

[67] Ferdinand, P.,

"New Type of Electric Current Measurement Sensor: Single-mode Optical Fiber Two-frequency Interferometer Sensitive to Faraday Effect,"

Revue Generale de l'Electricite, May 5, 1984, French.

Abstract:

A possible variant for traditional electrical current measurement methods is presented: an optical sensor based on the Faraday effect and employing a single-mode optical fiber Sagnac

interferometer coupled to a two-frequency laser. The author considers the problems related to the implementation of a single-mode fiber conserving polarization during light propagation as well as those connected with the manufacture of two-frequency laser source. The experimental results that are given demonstrate correct agreement with the announced theoretical principles.

OCT type: $\quad$ Fiber

Power systems relevance: * 
[68] Fisher, N.E. and Jackson, D.A.,

"Vibration Immunity and Ampere's Circuital Law for a Near Perfect Triangular Faraday Current Sensor,"

Measurement Science \& Technology, Vol.7, pp. 1099-1103, 1996.

Abstract:

We report a common-mode rejection scheme for a bulk-optic triangular Faraday effect current sensor that can eliminate optical noise induced by fiber-link vibration. The sensor's explotation of Amphere's circuital law is also demonstrated

OCT type: $\quad$ Bulk glass

Power systems relevance: *

[69] Fisher, N.E., Jackson, D.A., and Woolsey, "Faraday Current Sensors and the Significance of Subtended Angles,"

Sensors and Actuators A-Physical, Vol. 63, No. 2, pp. 5, October, 1997.

Abstract:

A series of experiments, involving measurements of Faraday rotation for light beams in linear and closed-loop optical current sensors, confirms that the degree of Faraday rotation of the polarization azimuth of a linearly polarized light beam, travelling in the vicinity of a current-carrying wire, is a linear function of the angle subtended at the wire by the beam. The experiments have been used to demonstrate the magnitudes of the errors that occur for different path geometries in a triangular closed-loop bulk-glass current sensor. The results of this work should enable geometrical design criteria for bulk-glass current sensors to be more readily established in future.

OCT type: Bulk glass

Power systems relevance: * 
[70] Forman, Peter R. and Jahoda, Franz C.,

"Linear Birefringence Effects on Fiber-Optic Current Sensors,"

Applied Optics, Vol 27, No. 15, pp. 3088-3096, August, 1988.

Abstract:

The occurrence of linear birefringence is inevitable when dealing with fiber optics. Intrinsic birefringence can be minimized, but deploying the fiber on an experiment will introduce stress birefringence due to bending and pressure. We have studied the effects of this extraneous linear birefringence on the measurement of current induced circular birefringence in a fiber which also has a strong twist circular birefringence bias. Orienting the analyzing polarizer by a proscribed procedure gives a minimum error. Quantitative error limits on the current a for given fiber coil radii and winding tensile stress are calculated. Additional restrictions on the fiber lead-in and lead-out sections are discussed.

OCT type: Fiber

Power systems relevance: *

[71] Frank, G.,

"Performance Issues for Optical Current Transducers in Utility Applications," Proceedings: EPRI 1992 Workshop on Optical Sensing in Utility Applications, pp. 12.1-12.15, 1992.

Abstract:

Whereas conventional high-voltage current transformers are optimized for either protective relaying or metering applications, magneto-optic current transducers may eventually yield performance required for both these applications in a single device. Some magneto-optic device requirements, as suggested by existing current transformer standards, are discussed. An overview of the issues involved in interfacing magneto-optic devices to existing protective relay systems is presented. The continued need for dependability and security in protection systems is mentioned with respect to the proposed use of hybrid relays

OCT type: $\quad$ Multiple

Power systems relevance: $* * *$ 
[72] Frenkel, R.B.,

"Optical Sensing of High Electric Currents Using the Faraday Effect in a Rigid Single Turn of Liquid,"

Measurement Science \& Technology, Vol. 4, pp.976-981, 1993.

Abstract:

A single-turn loop of liquid, contained in for rigid straight tubes forming sides a square, was tested as a Faraday-effect sensor of enclosed electric current. To preserve linear polarization, each of three corners of the square, light was totally internally reflected twice, with the second plane of incidence perpendicular to the first. Two liquids were tested, industrial-grade toluene and a mineral oil. Using simple optics the order of current sense was tens of amperes. Noise intensity fluctuations were greater in toluene than in the oil, an effect attributed to stronger natural convection in toluene.

OCT type: Liquid based (Faraday effect)

Power systems relevance: *

[73] Fujimoto, T., Shimizu, M., Nakagawa, H., Sone, I., Kawashima, K., and Mori, E., "Development of an Optical Current Transformer for Adjustable Speed Pumped Storage Systems,"

IEEE Transactions on Power Delivery, Vol. 12, No. 1, pp. 45-50, January, 1997.

Abstract:

The design and testing of a passive optical current transformer utilizing the Faraday effect is described. The Optical Current Transformer (OCT) was developed to measure the rotor excitation current of a 400 MW Adjustable Speed Pumped Storage System. Overall dimensions of the bulk optic sensor are $250 \times 250 \times 40 \mathrm{~mm}$ and the OCT functions as an overcurrent sensor to a maximum current of $35,000 \mathrm{~A}$. This OCT has been practically applied at the Ohkawachi Power Plant of the Kansai Electric Power Co, Inc. since December 1993.

OCT type: Bulk glass

Power systems relevance: $* * *$

[74] Glagolev, S.F., Zubkov, V.P., Chervinskii, M.M., and A'Arkhangel'skii, V.B., "Magnetoptical Transducer for High Alternating Current,"

Measurement Techniques (English translation of Izmeritel'naya Tekhnika,) Vol. 27, NO. 3, May, 1984.

Power systems relevance: $* *$ 
[75] Hasegawa, Y., lichikawa, Y., Katsukawa, H., Tanaka, N., and Sakurai, Y., "Development of a New Type of Optical Transducer for Measuring Fault Current," IEEE Transactions on Power Delivery, Vol. 9, No. 3, pp 1245-1252, July, 1994.

Abstract:

An optical current transducer has been developed capable of measuring current up to short-circuit currents of $50 \mathrm{kA}$. The optical current transducer is composed of a current measuring unit, an insulator with integral optical fibers, and an optical interface. The current measuring unit combines a winding with a magnetic iron core and a solenoid coil containing a Faraday sensor. The optical interface converts optical signals into electrical signals. Prototype optical current transducers have satisfied target performance requirements and have demonstrated maintaining that level of performance in field applications.

OCT type: Hybrid

Power systems relevance: $* * *$

[76] Hayes, J.N. and Heydt, G.T.,

"The Instrumentation of High Currents Using the Faraday Rotation Effect,"

IEEE Power Engineering Society Summer Meeting. (Text of A papers), July 18-23, 1976.

Abstract:

Describes an instrument for laboratory applications and an instrumentation method for field applications in electric power engineering for the optical measurement of high currents. Comments on difficulties in implementing optical instrumentation and methods of overcoming those difficulties are given. A discussion of liquid media for this application is presented.

OCT type: $\quad$ Multiple

Power systems relevance: $* * *$ 
[77] Hermstein, W.,

"Development Trends in the Construction of Measuring Transformers - with Special Reference to Unconventional Instrument Transformers for High Voltages,"

Elektrizitaetswirtschaft, Vol. 68, No. 8, pp. 246-257, April 14, 1969.

Abstract:

After discussing the possibilities and limitations of inductive and capacitive voltage transformers, as well as of conventional current transformers, a description is given of progress which has been achieved in the transformation quality of current transformers by dividing the iron core, in the case of completely displaced short-circuit currents. Finally a few facts are given which make the application of electronics and of the Faraday effect in current transformers for very high voltages appear possible in the not too distant future.

OCT type: $\quad$ Multiple

Power systems relevance: **

[78] Higham, A.D. and Newman, J.D.,

"Measurement of Current Using Faraday Rotation in Glass Fibre,"

Colloquium Digest on Novel Types of Transducer, November 27, 1972 .

OCT type: $\quad$ Fiber

Power systems relevance: * 
[79] Hillhouse, D.,

Optical Power Line Voltage and Current Measurement Systems, Vol. II

EPRI EL5431, 1987.

Abstract:

This report summarizes the results of an investigation into the technical and economic reasons for improving power system voltage and current measurements, with special emphasis on the prospects for utilizing optical technology. The investigation assesses information from interviews with representatives of utilities and manufacturing companies, along with other information from published sources. According to interviewees, the shortcomings of the established technology and the claimed advantages of the new one do not warrant an immediate switchover to new technology. However, there was also a consensus among those interviewed that a long-term trend toward the optical measurement systems has begun and that optical measurement technology will ultimately be used in the power grid. Measurement system needs were: lower cost alternatives; greater dynamic range for current transformers; the demand for more accurate metering; fiber optic data transmission which is broadband, very fast, and free from electrical interference, properties which are required by computer controlled systems; computer control which requires more real time data. The report concludes with a recommendation for a carefully structured and coordinated program of research and development.

OCT type: Multiple

Power systems relevance: $* * *$

[80] Hilson, D.,

"TVA's Program to Utilize Fiber Optics and Optical Sensors for Power System Applications," SPIE Polarized Light, Vol. 88, 1976.

Abstract:

Following numerous violent and destructive explosions of oil-filled freestanding current transformers (CTs), TVA's Division of Energy Demonstrations and Technology initiated a program to evaluate the use of fiber optics and optical sensors as potential alternatives to existing CTs. In addition, these devices offer the promise of being able to function effectively in such harsh environments as very high electromagnetic fields resulting from extra high voltages (EHV), dense radioactive bombardment from such sources as nuclear reactors, and elevated temperatures and pressures commonly found in steam generators. While several optical sensor systems have been investigated and demonstrated in the laboratory environment, the first real field test will occur in the spring of 1986 with the installation of a magneto optical current transducer (MOCT).

OCT type: $\quad$ Multiple

Power systems relevance: $* * *$ 
[81] Imamura, M., Nakahara, M., and Tamura, S.,

"Output Characteristics of Field Sensor Used for Optical Current Transformers Applied to the Flat-shape Three-phase Bus-bar,"

IEEE Transactions on Magnetics, Vol. 33, No. 5, pp. 3, September, 1997.

Abstract:

The open-air-type optical current transformer is studied to apply it to three-phase power distribution equipment. To make this type of OCT, laminations of non-oriented Si-Fe sheet used as shielding are tested for the effect of shielding. The linearity of the magneto-optical field sensor used in the OCT is discussed. It is shown that the proposed OCT will allow $0.5 \%$ accurate measurements for three-phase ac currents.

OCT type: Magnetic Field Sensor

Power systems relevance: $* * *$

[82] Imamura, M. and Tokubuchi, M.,

"Magnetic Field Analysis for the Optical Current-Transformer Used for Three-phase Bus-bars Arranged Longitudinally,"

IEEE Transactions on Magnetics, Vol. 32, No. 5, pp. 4962-4964, September, 1996.

Abstract:

AC magnetic fields due to bus-bar currents are analyzed to design a three-phase optical current transformer arranged longitudinally. The optical current transformer with a single or double shield structure is studied in order to reduce mutual interference of magnetic fields due to three-phase transmission currents and an additional field induced by eddy currents.

OCT type: Magnetic Field Sensor

Power systems relevance: $* *$ 
[83] Ionescu, A. and Popescu, Gh., "Current Laser Measurements in High-voltage Transmission Lines,"

Studii si Cercetari de Fizica, Vol. 27, No. 7, pp 719-730, 1975, Romanian.

Abstract:

A laser device for measuring the current in high-voltage transmission lines is described. The method is based on the Faraday effect: the rotation angle of the laser beam polarization in a flint glass rod is proportional to the instantaneous current of the line. The rotation is measured with a differential analyzer in a ground potential site. The parameters of some devices are presented. The possible sources of error and the advantages of the method are discussed.

OCT type: Bulk glass

Power systems relevance: $* * *$

[84] Inoue, N., Tsunekage, T., and Sakai, S.,

"On-Line Fault Location System for $66 \mathrm{kV}$ Underground Cables with Fast O/E and Fast A/D Technique,"

IEEE Transactions on Power Delivery, Vol. 9, pp. 579-584, 1994.

Abstract:

A fault location system, which continuously monitors a $866 \mathrm{kV}$ underground transmission line and instantaneously locates the distance to the point of a fault at a ground fault, is being developed. A prototype system for straight lines was developed as the first step. The surge current which flows, at a ground fault, from the point of fault to each end of the line is detected by a fast optical CT based on Faraday effect. The detected surge current is converted to digital data through a fast $\mathrm{O} / \mathrm{E}$ converter and a fast $\mathrm{A} / \mathrm{D}$ converter, and the distance to the point of fault is determined from the time difference of arrival of surge current. Location test was carried out on single phase coaxial cable of $1000 \mathrm{~m}$ long. The average location error of the system is below $10 \mathrm{~m}$.

OCT type: Magnetic concentrator

Power systems relevance: $* * *$ 
[85] Itoh, N. Minemoto, H., Ishiko, D. And Ishiuka, S.,

"Commercial Current Sensor Activity in Japan,"

12th International Conference on Optical Fiber Sensors, Williamsburg, USA, October 28-31, 1997.

Abstract:

This paper reviews recent developments by Panasonic in the field of optical current sensors. Among the most significant advances, optical current transformers with highly accurate magnetic field probes using iron garnet films have been developed for metering. The paper also discusses a novel Faraday materials and optical configurations.

OCT type: Magnetic concentrator, Thin Film

Power systems relevance: $* * *$

[86] Jaecklin, A.A.,

"Laboratory Model of a Magneto-optical Current Transformer,"

Archiv fur Technisches Messen und Industrielle Messtechnik, Vol. 428, pp. 107-108, September, 1971.

Abstract:

The new method is based upon the use of a polarized light beam as information carrier, which is modulated by the Faraday effect. The current to be measured produces a magnetic field on a solenoid which contains a flint-glass sensor. This field rotates the polarization plane. The insulation problems of the conventional current transformers are avoided.

OCT type: Hybrid

Power systems relevance: * 
[87] Kaneko, T., Tsuji, T., Ohdou, J., Otsubo, M., Honda, C., Tanahara, M., Ueda, Y. and Oguro, Y.,

"Development of Harmonic Measuring Instruments Using Optical Voltage and Current Sensor Systems for Power Distribution Lines,"

10th International Symposium on High Voltage Engineering, pp. 13-16, Montreal, Canada, 1997.

Abstract:

The application of optical measuring technique was attempted to develop the harmonic voltage and current measuring instruments for power distribution systems. To develop an optical voltage sensor system using $\mathrm{Bi}_{12} \mathrm{GeO}_{20}$ Crystal as a sensing Pockels cell for high voltage distribution lines, the zinc oxide elements were adopted as a voltage divider. Also, the optical current sensor systems were improved on the harmonic current measuring instruments using $\mathrm{R}_{\mathrm{u} 3} \mathrm{Fe}_{5} \mathrm{O}_{12}$ films as a Faraday device. Besides, in the practical three-phase power distribution systems the developed optical voltage and current sensor systems were compared with the conventional harmonic analyzers for low voltage. It was confirmed that these optical voltage and current sensor systems show successfully good characteristics and practical use.

OCT type: Fiber

Power systems relevance: $* * *$ 
[88] Kanoi, M. Takahashi, G. Sato, T., Higaki, M. Mori, E. , and Okumura, K., "Optical Voltage and Current Measuring System for Electric Power Systems,"

IEEE Transactions on Power Delivery, Vol. PWRD-1, No. 1, January, 1986.

Abstract:

Recently, optical voltage and current measuring methods based on a principle different from that of the existing apparatus have been developed. As the most promising method among them, a voltage measuring method which uses an electrooptic effect called the Pockels effect and a current measuring method which uses a magnetooptic effect called the Faraday effect have been proposed. The authors have developed an optical voltage measuring system based on the electrooptic effect in bismuth germanium oxide $\mathrm{Bi}_{4} \mathrm{Ge}_{3} \mathrm{O}_{12}$ and a current measuring, system based on the magnetooptic effect of borosilicate crown glass for the purpose of utilization in electric power systems. As a result of the development, highly accurate voltage and current measuring systems (having nonlinearity error less than $\pm 0.4 \%$ and temperature stability less than $\pm 1.0 \%$ ) were obtained. Furthermore, short-circuit current was measured with the current measuring system, and an accuracy within $0 \%$ to $-4 \%$ in the range of $30 \mathrm{kA}_{\text {peak }}$ to $150 \mathrm{kA}_{\text {peak }}$ was obtained. When the measuring systems were mounted on the model of $70 \mathrm{kV}$ class gas insulated switchgears, it was verified that the measuring systems had satisfactory linearity and temperature stability.

OCT type: Bulk glass

Power systems relevance: ***

[89] Katsukawa, H., Ishikawa, H., Okajima, H., and Cease, T.W., "Development of an Optical Current Transducer with a Bulk Type Faraday Sensor for Metering," IEEE Transactions on Power Delivery, Vol. 11, No. 2, pp. 702-707, April, 1996.

Abstract:

An optical current transducer (OCT) with a bulk type Faraday sensor demonstrated $0.3 \%$ class accuracy for metering. The Faraday sensor had $\mathrm{Bi}_{12} \mathrm{SiO}_{20}$ (BSO) single crystals with right and left optical rotatory power to cancel out temperature dependency. A prototype $161 \mathrm{kV}$ OCT installed in a TVA substation verified $0.3 \%$ class performance. The OCT had the Faraday sensor, a gapped magnetic iron core, a $1.6 \mathrm{~m}$ optical insulator, and an optical interface.

OCT type: $\quad$ Bulk glass

Power systems relevance: $* * *$ 
[90] Katsuta, G., Muraoka, K., Inoue, N., Sakai, S., Tsunekage, T., and Ando, K.,

"Fault Section Detection System for 66-KV Underground Branch Transmission Lines Using Optical Magnetic Field Sensors,"

IEEE Transactions on Power Delivery, Vol. 7, No. 1, 1992.

Abstract:

A fault section detection system, which uses optical magnetic field sensors and instantly detects the section in which the ground fault occurred, was developed for $66-\mathrm{kV}$ underground multi-terminal systems having Y-branch joint boxes. The optical magnetic field sensor, which is based on Faraday effect in $\mathrm{Bi}$-doped $\mathrm{YIG}\left((\mathrm{BiYbGd})_{3} \mathrm{Fe}_{5} \mathrm{O}_{12}\right)$ having a large Verdet constant, detects cable conductor currents of $0 \mathrm{~A}$ to $2000 \mathrm{~A}$ at high precision with the use of a laminated magnetic ring core of silicon steel plates. Sensors and a fault section detector/indicator of a system are connected with optical fiber is capable of non-repeated transmission of over six kilometers.

OCT type: $\quad$ Thin Film

Power systems relevance: $* * *$

[91] Katsukawa, H., Yokoi, S. And Mizuno, K.,

"Application of Magneto-optical Sensors for Fault Location of Air Insulated Bus in Substations," EPRI: Optical Sensors for Utility T\&D Applications, Portland, Oregon, July 20-21, 1995.

Abstract:

A new fault location (FL) system for $275 \mathrm{kV}$ substation bus bars has been developed, using optical current transducers (OCTs). This system detects bulk current by combining OCTs with existing wound current transformers (CTs). The OCT is capable of measuring short circuit current up to $50 \mathrm{kA}$. This paper describes the FL system configuration, the OCT designed, and its performance. Also, this paper shows the OCT transient performance by simulation an examination. The system demonstrated good discrimination performance in the artificial location performance test. Recently, the system were installed in the Senio and the Higashinagoya substations of Chube Electric Power Co., Inc.

OCT type: Hybrid

Power systems relevance: **** 
[92] Katsukawa, H. and Yokoi, S.,

"Optical current Transducer with Bulk Type $\mathrm{Bi}_{12} \mathrm{SiO}_{20}$ Faraday Sensor for Power System," Physical Review, Vol. 4, No. 1A, PP. 3, January-February, 1997.

Abstract:

Two types of optical current transducers (OCTs) have a bulk Faraday sensor inserted into the gap of an iron core and a porcelain insulator with optical fiber. The sensor consists of $\mathrm{Bi}_{12} \mathrm{SiO}_{20}$ (BSO) single crystal, a polarizer, and an analyzer. The OCTs satisfied the target performance requirement for fault location and metering and demonstrated maintained performance at some power utilities in Japan and the US. We have developed a fault location system that immediately detects the fault current with the OCTs, thereby locating the fault section. The OCT can easily replace the existing support insulators for the disconnecting switch without any modifications to structure height or bus-bar. For metering requiring $0.3 \%$ class accuracy, use of a BSO with right optical rotatory power combined with BSO with left optical rotatory power results in a Faraday sensor with improved temperature characteristics. The OCT demonstrated $0.3 \%$ class accuracy for metering described in the current transformer specifications of IEEE.

OCT type: $\quad$ Magnetic concentrator

Power systems relevance: $* * *$

[93] Kersey, A. D., and Davis, M.A.,

"All-fiber Faraday-rotation Current Sensor with Remote Laser-FM Based Heterodyne Detection," Springer Proceedings in Physics, Vol. 44, 1989.

Abstract:

We describe an all-fiber Faraday-rotation current sensor which utilizes an optical frequency-induced polarization modulation approach to the detection of the magneto-optical polarization rotation. Remote passive current sensing over insensitive fiber leads utilizing heterodyne-type signal processing is demonstrated.

OCT type: Fiber

Power systems relevance: * 
[94] Kobayashi, S., Horide, A., Takagi, I., Higaki, M., Takahashi, G., Mori, E., and Yamagiwa, T.,

"Development and Field-Test Evaluation of Optical Current and Voltage Transformers for Gas Insulated Switch Gear,"

IEEE Transactions on Power Delivery, Vol. 7, No. 2, pp. 7, 1992.

Abstract:

An optical current transformer (CT) based on the Faraday effect and an optical potential divider (PD) based on the Pockels effect, for application to electric power systems, are described.

This optical CT is suitable for highly reliable gas insulated switchgear (GIS), and has free space light transmission parts among the optical fiber signal transmission lines. The developed optical CT and PD were built into $77 /\left(3^{1 / 2}\right) \mathrm{kV} 1200 \mathrm{~A}$ single phase prototype GIS. Their basic characteristics of current and voltage measurement conformed well with the standards of the JEC (Japan Electrotechnical Commission) 1201 for instrument transformers. Finally, a long-term field test of the prototype GIS was carried out at a substation for 20 months, during which time no. significant variation of current and voltage measuring characteristics was observed.

OCT type: Bulk glass

Power systems relevance: $* * *$

[95] Kozel, S. M., Kreopalov, V. I., Listvin, V. N., and Glavatskikh, N. A., "Current Sensor Utilizzaing a Fiber-optic Waveguide,"

Soviet Journal of Quantum Electronics (English translation of Kvantovaya Elektronika), Vol. 13, No. 1, pp. 102-104, 1983.

\section{Abstract:}

Abstract: A study was made of the influence of homogeneous and circular magnetic field on a single-mode optical fiber exhibiting linear birefrigence and wound into a coil with a circumference equal to the beat length. It was found that the sensitivity of a current sensor based on such a fiber can be as high as that of sensors utilizing an isotropic fiber.

OCT type: $\quad$ Fiber

Power systems relevance: * 
[96] Kugler, J. and Forbes, W.,

"An Optical Current Transformer for Conventional and Computerized Supervisory Control and System Protection for HV Transmission Systems,"

International Electrical, Electronics Conference and Exposition Digest, October 1-3, 1973.

Abstract:

Describes an optical telemetry system which can take the place of a costly conventional relaying and metering current transformer for HV systems. The optical link consists of a light emitting diode transmitter located on the line and transmitting the current signal to a receiver with a photodetector. This approach is compatible with both conventional and computerized supervisory control and protection systems on HV lines.

OCT type: Hybrid

Power systems relevance: *

[97] A. Kung, P.-A Nicati, and P.A. Robert, "Reciprocal and Quasi-reciprocal Brillouin Fiber-optic Current Sensors," IEEE Photonics Technology Letters, Vol. 8, No. 12, pp. 1680-1682, December, 1996.

Abstract:

A novel current sensor based on the interaction between two counter-propagating Brillouin fiber-optic lasers has been investigated. Polarization problems specific to current sensors are addressed and are solved by means of a mechanically twisted fiber-ring resonator including a polarization controller. The two proposed reciprocal and quasireciprocal configurations shows a linear response with a sensitivity of $126 \mathrm{~Hz} / \mathrm{A}$ that is very close to the maximum sensitivity obtained by using fibers without linear birefringence. The limitations of the reciprocal configuration due to the lock-in range, the Kerr effect induced by the pump walk-off and by the pump intensity fluctuations are fully characterized. These limitations are compared with the limitations due to thermal drifts of the quasireciprocal configuration which allows direct detection of the current direction.

OCT type: Fiber

Power systems relevance: * 
[98] Kurosawa, K.,

"Optical Current Transducers Using Flint Glass Fiber as the Faraday Sensor Element," Physical Review, Vol. 4, No. 1A, pp. 7, January-February, 1997.

Abstract:

This paper describes development of the optical current transducers using flint glass fiber as the Faraday effect sensing element. Excellent polarization properties of the fiber with low birefringence are described, and the design and test data of a current transducer using the fiber manufactured for use in electric power facilities are reviewed. Experimental results on flexible characteristics of a scheme with round trip light transmission in the fiber is also reported.

OCT type: Bulk glass

Power systems relevance: *

[99] K. Kurosawa,

"A Method with Two Light Sources for Accurate DC Current Measurement Using Faraday Effect,"

9th Optical Fiber Sensors Conference, 1993.

\section{Abstract:}

A new scheme with two light sources of different wavelengths is proposed for accurate measurement of direct current using the Faraday effect. Experimental results about techniques for making the method be applicable are also described.

OCT type: Magnetic field sensor

Power systems relevance: * 
[100] Kyuma, K., Tai, S., Nunoshita, M., Takioka, T., and Ida, Y., "Fiber Optic Measuring System for Electric Current by Using a Magneto-optic Sensor," IEEE Journal of Quantum Electronics, Vol. 18, No. 10, pp. 1619-1623, October, 1982.

Abstract:

A practical fiber optic measuring system for heavy electric current was developed by using the magnetooptic (Faraday) material. In order to obtain better signal to noise ratio and smaller temperature dependence, the most suitable combination of the light source and Faraday material was experimentally and theoretically determined. Consequently, it was emphasized that an LED and diamagnetic SF-6 flint glass gave the superiority of overall system capability over LDs and para- or ferromagnetics. A novel type of fiber optic current sensor was constructed of the Faraday rotator of SF-6 flint glass with two thin-film polarizers. By using this sensor and a high radiance LED, high accuracy within \pm 0.5 percent was obtained for a magnetic field between 20 Oe and $500 \mathrm{Oe}$, and at temperatures from $-25^{\circ} \mathrm{C}$ up to $80^{\circ} \mathrm{C}$.

OCT type: $\quad$ Fiber

Power systems relevance: *

[101] Kyuma, K., Tai, S., Nunoshita, M., Sawada, T., Takioka, T. and Ida, Y., "Fiber Optic Current Sensor Using $\mathrm{Bi}_{12} \mathrm{GeO}_{20}$ Single Crystal: A Novel Type," Digest of Technical Papers - 6th Topical Meeting on Optical Fiber Communication, 1983.

OCT type: $\quad$ Fiber

Power systems relevance: *

[102] Laming, R.L. and Payne, D.N. and Li, L., "Current Monitor Using Elliptical Birefringent Fibre and Active Temperature Compensation," SPIE, Vol. 798, pp. 283-287, 1987.

OCT type: $\quad$ Fiber

Power systems relevance: * 
[103] Laming, R.I., and Payne, D.N.,

"Electric Current Sensors Employing Spun Highly Birefringent Optical Fibers,"

Journal of Lightwave Technology, Vol. 7, No. 12, pp. 2084-2094, December, 1989.

Abstract:

Abstract: Highly elliptically birefringent fibers have been fabricated by spinning a linearly birefringent fiber during the draw. These fibers are particularly interesting for application as Faraday-effect fiber current monitors, since, in contrast with conventional fibers, they can be wound in small multi-turn coils while retaining their sensitivity. The fiber and its exploitation in three optical schemes are modeled using Jones calculus and also experimentally investigated. A simple optical configuration is proposed, combining the elliptically birefringent fiber and a broad-spectrum light source. An accurate, compact, and robust current monitor is obtained. The sensor is characterized by a measurement repeatability of \pm 0.5 percent, a temperature drift of 0.05 percent/degree Celsius and a sensitivity of $1 \mathrm{~mA}_{\mathrm{ms}} / \mathrm{Hz}^{1 / 2}$. Further, we predict the performance of this sensor with optimized fiber length for a given measurement bandwidth.

OCT type: $\quad$ Fiber

Power systems relevance: *

[104] Lassing, H.S., Oomens, A.A.A., and Woltjer, R., "Development of a Magneto-optic Current Sensor for High, Pulsed Currents," Review of Scientific Instrumentation, Vol. 57, No. 5, May, 1986.

Abstract:

A description is given of a current-measurement system based on the Faraday rotation in a one turn fiber coil. It is shown that an ultralow birefringence "spun" single-mode fiber is extremely suitable in a magneto-optic current sensor. The properties of this fiber were investigated.

Measurements of high, pulsed currents $\left(\mathbb{I}_{\max } \sim 1 \mathrm{MA} ; f=25 \mathrm{kHz}\right)$, with good accuracy (1\%), and in agreement with a conventional method, are presented. Because of the low birefringence, this good accuracy was also reached in the low-current region $(\theta<\pi / 4 \mathrm{rad})$. In order to be able to compute the value of large currents unambiguously from the Faraday rotation, a setup with a beam-splitter prism and a second detector was constructed. Some measurements were carried out with this setup.

OCT type: Fiber

Power systems relevance: * 
[105] Leilabady, P.A., Wayte, A.P., Berwick, M., Jones, J.D.C., and Jackson, D.A., "A Pseudo-reciprocal Fibre-optic Faraday Rotation Sensor: Current Measurement and Data Communication Applications,"

Optics Communication, Vol. 59, No. 3, September, 1986, .

Abstract:

A fiber-optic magnetometer based on Faraday rotation in a Sagnac interferometer is described. The pseudo-reciprocity of the arrangement provides stability and in sensitivity to environmental effects; also, low coherence optical sources may be used. An extension of this technique is described to implement and optical data-bias with non-invasive transducers which consume no optical power.

OCT type: Fiber

Power systems relevance: *

[106] Leung, F., Chiu, W., and Demokan, M.S., "Fiber-optic Current Sensor Developed for Power System Measurement," IEE International Conference on Advances in Power System Control, Operation and Management, Hong Kong, November, 1991.

Abstract:

The paper first gives an overview of the various types of magnetic field fiber-optic sensors. The main part of the paper describes the design, implementation and characterization of a fiber-optic sensor for measuring magnetic field and current by using the principle of Faraday rotation in a crystal. The applications of the sensor in the electric power industry are discussed.

OCT type: Fiber

Power systems relevance: * 
[107] Liu, Y.E. Rahman, B.M.A., Ning, Y.N. and Grattan, K.T.V.,

"Accurate Mode Characterization of Graded-Index Multimode Fibers for the Application of Mode-Noise Analysis,"

Applied Optics, Vol., 34, No. 9, pp. 4, March 20, 1995.

Abstract:

Guided modes in graded-index multimode optical fibers are accurately analyzed with the vector $\mathrm{H}$-field finite-element method, aided by the use of the WKB method. As a result, exact mode-propagation constants and the corresponding modal eigenfield distributions are provided for the study of the modal noise that is due to the mode-coupling effect.

OCT type: $\quad$ Fiber

Power systems relevance: *

[108] Lizet, J., Vallette, S., and Langeac, D., "Reduction of Temperature and Vibration Sensitivity of a Polarimetric Current Sensor.," Electronics Letters, Vol. 19, No. 15, pp. 578-579, July, 1983.

Abstract:

Authors report on a new type of Faraday-effect current sensor using a twisted single-mode fiber as the probe. The temperature drift is canceled by a 'double-twist' configuration, and the sensitivity to vibrations and bends is drastically reduced by use of polarization-maintaining fibers as the input and output connecting leads.

OCT type: $\quad$ Fiber

Power systems relevance: * 
[109] Luo, C.M., Zheng, Z.X., Ma, X.Y., and Su, J.X., "The Study of Accuracy of a Magneto-optical Current Transformer,"

10th International Symposium on High Voltage Engineering, August, 1997.

Abstract:

The effects of temperature and stress on the measurement accuracy of magneto-optical current transformer are deeply studied, in order to promote its practical application. The temperature control of the LED, PIN and electronic circuit is adopted, according to the fact that the wavelength of the LED depends on its temperature and driven current. The method to maintain the light intensity of LED by adjusting driven current is inadequate. The reasons to cause and the measures to reduce the influences of linear birefringence are discussed. A unique assembling method of sensor head with less assembling-caused birefringence is developed. The accuracy of a developed bulk type magneto-optical current transformer is better than $\pm 0.3 \%$ over a temperature range from $-30{ }^{\circ} \mathrm{C}$ to $+70{ }^{\circ} \mathrm{C}$.

OCT type: Bulk glass

Power systems relevance: *

[110] MacDougall, T.W. and Hutchinson, T.F, "Stray Magnetic-field Response of Linear Birefringent Optical Current Sensors," Applied Optics, Vol. 34, No. 21, pp. 4373-4379, July 20, 1995.

Abstract:

It is well known that the line integral, describing Faraday rotation in an optical medium, reduces to zero at low frequencies for a closed path that does not encircle a current source. If the closed optical path possesses linear birefringence in addition to Faraday rotation, the cumulative effects on the state of polarization result in a response to externally located current-carrying conductors. This effect can induce a measurable error of the order of $0.3 \%$ during certain steady-state operating conditions.

OCT type: Fiber

Power systems relevance:

* 
[111] MacDougall, T.W., Lutz, D.R., and Wandmacher, R.A.,

"Development of a Fiber Optic Current Sensor for Power Systems,"

IEEE Transaction of Power Delivery, Vol. 7, No. 2, pp. 848-852, April, 1992.

Abstract:

Numerous techniques have been developed to sense electric current optically, including several using optical fibers as the sensing element. To date, easy methods have failed to overcome the fundamental performance problems of the bulk optic components, as well as the instability of the sensing fiber. Presented here is a description of an all-fiber optic current sensor. A method for producing highly stable sensing coils and techniques for interfacing these coils with novel polarizing fiber are described. Also, the performance of a fully functional prototype device is discussed. Theoretical limits in preliminary characterization data are presented.

OCT type: $\quad$ Fiber

Power systems relevance: $* *$

[112] Maffetone, T.D. and McClelland, T.M.,

"345-KV Substation Optical Current Measurement System for Revenue Metering and Protective Relaying,"

IEEE Transactions on Power Delivery, Vol. 6, No. 4, pp. 1430-1437, October, 1991.

Abstract:

The authors report for the first time on the performance of a $345 \mathrm{kV}$ optical current sensor used for substation metering. The waveform quality of this sensor was compared to that of a conventional current transformer in both the time and frequency domains. The interfacing of this device with conventional $5 \mathrm{~A}$ protective relay systems using a pulse width modulation amplifier is discussed. The optical current sensor is based on the Faraday effect. This system was designed and developed to advance the state of the art in optical metering, relaying, and data acquisition. The decisions leading to the design of the optical metering system, the components of the system, the site installation, field test results, and recommendations for future work are discussed.

OCT type: Fiber

Power systems relevance: $* * *$ 
[113] Malewski, R.,

"Measuring Impulse Currents Magneto-Optically,"

Elteknik, Vol. 11, November, 1970.

Abstract:

Magneto-optical methods for measuring current are gaining widespread use and importance. The author describes a device developed in Poland. The device described in this article is developed to measure large current impulses at a potential of $100 \mathrm{kV}$ to ground. The rise time had to be less than approximately $40 \mathrm{~ns}$. The device is based on the Faraday magneto-optical effect that some materials exhibit, i.e. the rotation of the polarization plane of a light-beam in a magnetic field. The rotated angle is proportional to the strength of the magnetic field in the same direction as the light beam, the distance traveled within the magneto-optical material, and the Verdet constant. The Verdet constant depends on the material used. For visible light it reaches comparatively high values in dense flint-glass. The measuring device is based on the same principles as the magneto-optical current transformers. It differs in some respects however, as it is designed for oscilloscope recording, in a laboratory, of current impulses.

OCT type: $\quad$ Multiple

Power systems relevance: $* *$

[114] Malewski, R., "High-voltage Current Transformers with Optical Signal Transmission," Optical Engineering, Vol. 20, No. 1, pp. 054-057, January-February 1981.

Abstract:

Existing prototype optical current transformers are reviewed and their design as well as their functional characteristics are analyzed in the light of the practical requirements dictated by operating conditions in an extra-high-voltage (EHV) switchyard. A perspective of the development of a new magnetooptic current transformer is explored. The feasibility of such apparatus depends on technological progress in manufacturing mono-mode optical fibers which will not depolarize the transmitted light.

OCT type: Bulk glass

Power systems relevance: *** 
[115] Massey, G.A., Erickson, D.C., and Kadler, R.A.,

"Electromagnetic Field Components: Their Measurement Using Linear Electro-optic and Magneto-optic Effects,"

Applied Optics, Vol. 14, No. 11, pp. 2712-2719, November, 1975.

Abstract:

A sensor is located in the field to be measured. Light from a remote laser is modulated by the sensor and returned to the detector for measurement. The sensor may use the Pockels effect to measure electric fields or the Faraday effect to measure magnetic fields. Sensitivities are calculated. Experimental results are described. It is concluded that it should be possible to measure currents and voltages on $500 \mathrm{kV}$ transmission lines with an accuracy of about $0.3 \%$.

OCT type: Bulk glass

Power systems relevance: $* *$

[116] Massey, G., Johnson, J., and Erickson, D., "Laser Sensing of Electric and Magnetic Fields for Power Transmission Applications" Transactions on Power Delivery, Vol. 9, No. 1, January, 1994.

Abstract:

Polarization modulation of light from a $633 \mathrm{~nm}$ He-Ne laser, using the Pockels and Faraday effects in appropriate materials, can serve as an electrometer and magnetometer with sensitivities to $0.06 \mathrm{volt} / \mathrm{cm}$ and 0.03 gauss or better. With the sensor material placed in the field and the laser illuminator and receiver mounted remotely, this technique can be used for precise, wideband measurement of transient effects and power flow in substation environments where high fields prohibit direct measurements. This paper describes the performance of these devices used in prototype systems for voltage transient monitoring and also for precise voltage and current metering. The latter system requires thermal sensing as well, with an accuracy of $0.1{ }^{\circ} \mathrm{C}$; optical methods for accomplishing this will be described.

OCT type: Multiple

Power systems relevance: $* *$ 
[117] Maystre, F. and Bertholds, A.,

"Magneto-optical current sensor using a helical fiber Fabry-Perot resonator,"

Proceedings of the 6th International Conference on Optical Fiber Sensors, pp. 267-272, 1989.

Abstract:

The concept of a magneto-optic current sensor which employs a fiber-optic Fabry-Perot resonator shaped into a single-turn helix is presented. The helical shape permits construction of a compact device which has the required polarization properties. Compared to a single-pass sensor, an increase in sensitivity is obtained in proportion to the finesse of the resonator.

OCT type: Fiber

Power systems relevance: *

[118] Menke, P. and Bosselmann, T., "Magnetooptical AC-current Sensing with an Annealed Fibre Coil and Intrinsic Temperature Compensation,"

SPIE, Vol. 2292, pp. 26-33, 1994.

Abstract:

The basic theory of birefringent Faraday materials is well known, but some very interesting conclusions from this theory concerning the application of Faraday materials to magneto-optical current sensing have not been drawn yet. In this paper a general theoretical description of current sensors using homogeneous linear birefringent materials is given. The theoretical description is used to develop practically applicable methods of compensating the temperature drift caused by the linear birefringence in the Faraday material. Experimental results for a glass ring sensor and a sensor using an annealed fiber coil are given. Accuracy is up to only $0.2 \%$ error over a temperature range from $-20{ }^{\circ} \mathrm{C}$ to $80^{\circ} \mathrm{C}$ have been achieved.

OCT type: Multiple

Power systems relevance: * 
[119] Menke, P. and Bosselmann, T.,

"Simple and Flexible Procedure for Temperature Drift Compensation of Magneto-optic AC Current Sensors Using An Intelligent AC-DC Signal Evaluation Derived From Rigorous Theory,"

$10^{\text {th }}$ International Conference on Optical Fiber Sensors, Glasgow, Scotland, 1994.

Abstract:

A simple procedure for temperature compensation of magneto-optic current transformers is derived from rigorous theory. It provides a flexible correction independent of the type of intensity normalization either by mechanical or electrical adjustment or in combination offering a high accuracy of $0.2 \%$ over a temperature range of $100{ }^{\circ} \mathrm{C}$.

OCT type: $\quad$ Multiple

Power systems relevance: *

[120] Menke, P. and Bosselmann, T., "Temperature Compensation in Magnetooptic AC Current Sensors Using an Intelligent AC-DC Signal Evaluation," Journal of Lightwave Technology, Vol. 13, No. 7, pp. 1362-1370, July, 1995.

Abstract:

The basic theory of birefringent Faraday materials is well known, but some very interesting conclusions from this theory concerning the application of Faraday materials to magnetooptical current sensing have not been drawn yet. In this paper a general theoretical description of current sensors using homogeneous linear birefringent Faraday materials is given. The theoretical description is used to develop practically applicable methods of compensating the temperature drift caused by the linear birefringence in the Faraday material. Experimental results for a glass ring sensor and a sensor using an annealed fiber coil are given. Accuracies up to only $0.2 \%$ error over a temperature range from $-20^{\circ}$ to $80^{\circ} \mathrm{C}$ have been achieved.

OCT type: Multiple

Power systems relevance: * 
[121] Minier, V., Danel, A., Persegol, D., and Kevorkian, A., "Development of an integrated optical current sensor for large AC current sensing," Proceedings: 7th European Conference on Integrated Optics, pp. 379-383, Delft, The Netherlands, April, 1995.

Abstract:

We have developed a Faraday effect integrated optical current sensor for measurements of large AC currents. The optical waveguides of the sensor head have been optimized to reduce optical losses and intrinsic linear birefringence. Preliminary results show a good linearity of the sensor response over a wide range of currents.

OCT type: Integrated optics

Power systems relevance: *

[122] Minier, V., Persegol, D., Lovat, J.L., and Kevorkian A., "Integrated optical current sensor for high-power systems,"

Eleventh International Conference on Optical Sensors,pp. 164-167, Sapporo, Japan, May 21-24, 1996.

Abstract:

We describe a Faraday effect current sensor whose transducer is made of a glass substrate with ion exchanged waveguides. A compensation scheme for the linear birefringence has been implemented and tested on an industrial prototype.

OCT type: Integrated Optics

Power systems relevance: *

[123] Minier, V. Persegol, D., Lovato, J.L., and Kevorkian, A., "Integrated optical current sensor with low birefeingence optical waveguides," 12th International Conference on Optical Fibers, Williamsburg, USA, October 28-31, 1997.

Abstract:

none

OCT type: Integrated optics

Power systems relevance: * 
[124] Minier, V. Persegol, D., Lovato, J.L., and Kevorkian, A.,

"Low-birefringence optical waveguides for high performance magneto-optic current sensing," Proceedings of the 8th European Conference in Integrated Optics, April, 1997.

Abstract:

We describe the successful fabrication of low-birefringence $\left(\delta \mathrm{n}_{\mathrm{eff}}=5 \times 10^{-7}\right)$ ion-exchanged waveguides and their use in a new generation of optical current sensor.

OCT type: Integrated optics

Power systems relevance: *

[125] Mitsui, T. Hosoe, K. Usami, H. and Miyamoto, S.,

"Development of Fiber-Optic Voltage Sensors and Magnetic Field Sensors,"

IEEE Transactions on Power Delivery, PWRD-2, Vol. 1, pp. 87-93, January, 1987.

Abstract:

The principal, temperature characteristics, and the frequency characteristics of fiber-optic voltage sensors and magnetic field sensors are reported, along with the results of an aging test on these sensors. The fiber-optic voltage sensors utilizes the "Pockels" effect of $\mathrm{Bi}_{12} \mathrm{SiO}_{12}$ single crystal and the fiber-optic magnetic field sensor utilizes the "Faraday" effect of ZnSe polycrystal and $\mathrm{Bi}_{12} \mathrm{SiO}_{12}$ single crystal. The basic performance of these sensors has been investigated from the perspective of their use as parts in electrical apparatuses. In addition, in this paper some practical applications in electrical substations and transmission lines are presented. These include a fault section detecting system for gas insulated transmission line (GIL), an optical voltage transformer and optical current transformer, which are embedded in gas insulated switchgear (GIS), and a surge voltage receiving system.

OCT type: Bulk glass

Power systems relevance: $* * *$ 
[126] Mizuno, K., Katsukawa, H., Sakurai, Y., and Tanaka, N.,

"Application of Magneto-optical Sensors for Fault Location in an Air-Insulated Substation Bus," Electrical Engineering in Japan, Vol. 119, No. 2, pp. 8, April 30, 1997.

Abstract:

A new fault location system using optical current transducers (CTs) to detect faulted sections in the bus bars of directly grounded $275-\mathrm{kV}$ substations has been developed. This system detects fault current by combining optical CTs with wound-type CTs. The new type of optical CT applies a bulk-type Faraday sensor to the combination of windings around a magnetic iron core and a solenoid coil. The optical CT was capable of current measuring over $50 \mathrm{kA}$. A current differential discriminator combining an optical CT and a wound-type CT verified the operational performance with $40-\mathrm{kA}$ currents. The intended level of fault detection performance was obtained. Based on these results, a system is being made for actual application in $275-\mathrm{kV}$ substations.

OCT type: Bulk glass

Power systems relevance: $* * *$

[127] Mueller, W.,

"Development Trends in the Design of Measurement Transformers -- Especially in the Field of Non-Classical-Type Transformers.,"

Bulletin Scientifique de l'Association des Ingenieurs Electriciens Sortis de l'Institut

Electrotechnique Montefiore, Vol. 86, No. 3, pp. 79-184, July-September, 1973, French.

Abstract:

Three methods proposed for use in non-classical-type transformers, suitable for current measurement in the open-type substations, and one method for voltage measurement in the enclosed installations insulated with $\mathrm{SF}_{6}$ are presented. Adaptation of these new transducers for use with protection relays is investigated. Description is given of: a current transformer with frequency modulation (traser) which is an electronic current measurement transducer for use with outdoor high-voltage switchgear; the magneto-optical current transformer using Faraday effect; the current transformer with dielectric waveguides. Current and voltage transformers used for measurement in enclosed switchgear installations insulated with $\mathrm{SF}_{6}$ are also described.

OCT type: $\quad$ Bulk glass

Power systems relevance: $* * *$ 
[128] Mukunda, R. M., Reddy, C.N., Venugopal, M., and Murthy, N.S.N.,

"Current Measurements in EHV Lines Using Lasers,"

Journal of the Institution of Engineers (India) Vol. 59, pp. 287-291, April, 1979.

\section{Abstract:}

The shortcomings of conventional current transformers for measuring current in extra high voltage transmission lines are sought to be overcome using laser beams. Out of the two methods: (a) the tracer system and (b) the Faraday effect technique, the latter is found to be more suitable and is chosen for this purpose. The results of experimental investigations using this method for measuring current are reported.

OCT type: $\quad$ Multiple

Power systems relevance: $* * *$

[129] Nicati, P. and Robert, P., "Numerical Analysis of Second-Order Polarization Effects in a Sagnac Current Sensor," IEEE Transactions on Instrumentation and Measurement, Vol. 39, No. 1, pp 219, February, 1990.

Abstract:

This paper presents two aspects of a novel, stabilized Sagnac optical fiber current sensor. The sensor system and its compensation are described followed by a numerical analysis of the variation of polarization along the optical fiber. These results are used to scale the optimal parameters of the sensor and to define theoretical limits of accuracy. Linear birefringence, fiber launching efficiency, laser intensity, and mainly their variations limit the accuracy of the system. Linear birefringence can influence both the phase and the amplitude of the two interfering beams, whereas launching efficiency and the laser intensity can only modify the amplitude. The stabilization of the sensor output is obtained by electronically combining the primary output signal with a fraction of the two counterpropagating signals before their interferometric reconstruction. This renders possible a compensation of the sensor against the influence of all perturbations which can affect the intensity of one mode by loss or by coupling into another mode. A phase correction can also be made, provided the mean value of the linear birefringence is well known. Results of the numerical analysis of the variation of polarization are shown for an optical fiber containing both linear and circular birefringences and are applied to the Sagnac optical fiber current sensor to determine the theoretical accuracy together with the limits to be expected using the proposed compensation scheme.

OCT type: Fiber

Power systems relevance: * 
[130] Nielsen, T. and Bohnert, K.,

"The Stable Class 0.2 Sagnac Current Sensor Using Annealed Fiber Sensor Coil,"

SPIE, 3483, pp. 190-194, 1998.

OCT type: $\quad$ Fiber

Power systems relevance: $* *$

[131] Nikitenko, N. F.,

"Optical Polarization Current Measuring Method with Phase Transformations.,"

Izvestiya Vysshikh Uchebnykh Zavedenii, Elektromekhanika, Vol. 9, pp. 931-935, September, 1980, Russian.

Power systems relevance: $*$.

[132] Ning, Y.N., Chu, B.C.B., and Jackson, D.A.,

"Interrogation of a Conventional Current Transformer by a Fiber-Optic Interferometer,"

Optics Letters, Vol. 16, No. 18, pp 1448-1450, September, 1991.

Abstract:

A new approach to the measurement of large currents at high potential is presented in which the output signal from a conventional current transformer is measured by transducing the voltage developed across the transformer secondary into phase modulation in a fiber-optic interferometer through a piezoelectric element. The demonstrated current range was $140 \mathrm{~A}$, although the system is capable of measuring current as great as $3000 \mathrm{~A}$. The current resolution is greater than $10^{-1}$ $\mathrm{A} /\left(\mathrm{Hz}^{1 / 2}\right)$ over a frequency range of $30 \mathrm{~Hz}-10^{4} \mathrm{~Hz}$.

OCT type: Hybrid

Power systems relevance: * 
[133] Ning, Y.N., Chu, B.C.B., and Jackson, D.A.,

"Miniature Faraday Current Sensor Based on Multiple Critical Angle Reflections in a Bulk-Optic Ring,"

Optics Letters, Vol. 16, No. 24, pp. 1996-1998, December, 1995.

Abstract:

A novel optical element for a Bulk glass current sensor that utilizes the Faraday effect is presented with a demonstrated sensitivity of $1 \mathrm{amp}$-turn and a flat frequency response in the range of $\left(10^{1}-10^{4}\right) \mathrm{Hz}$. The new sensing element overcomes the problems associated with birefringence in optical fiber current sensors and the requirement to make bulk-optic current sensors in complex three-dimensional topologies.

OCT type: Bulk glass

Power systems relevance: *

[134] Ning, Y.N. and Jackson, D.A., "Faraday Effect Optical Current Clamp Using a Bulk-glass Sensing Element," Optics Letters, Vol. 18, No. 10, May 15, 1993.

Abstract:

A new topology for an openable Faraday current sensor is presented with the demonstrated resolution of $1.7 \mathrm{~mA}$ /square-root $\mathrm{Hz}$ over a measurement range from $1 \mathrm{~A}$ to $1500 \mathrm{~A}$. The sensitivity of the system is $2.21 \times 10^{-5} \mathrm{rad} / \mathrm{A}$. Since this sensor is fabricated in an openable form, emulating a conventional current clamp, it can be used either in permanent installations or for short-term diagnostic studies.

OCT type: Clamp-on, Bulk glass

Power systems relevance: *

[135] Ning, Y.N. and Jackson, D.A., "A Miniature Optical Current Clamp," $9^{\text {th }}$ International Fiber Sensors Conference, Florence, Italy, 1993.

Abstract:None

OCT type: Clamp-on, Bulk glass

Power systems relevance: * 
[136] Ning, Y.N. and Jackson, D.A.,

"Review of Optical Current Sensors Using Bulk-Glass Sensing Elements,"

Sensors and Actuators A-Physical, Vol. 39, No. 3, pp. 219-224, 1993.

Abstract:

A general review of recent developments in the field of bulk-optic current sensors is presented.

The modes of operation of a range of optical current sensors based upon various novel topologies utilizing high-Verdet-constant bulk glass are described. The difficulties caused by the differential phase shift in the light on internal reflection can be effectively overcome using optical geometries that exploit either dual-quadrature or critical-angle reflections. The principle of operation of the sensors is outlined and their performance is shown.

OCT type: Bulk glass

Power systems relevance: *

[137] Ning, Y., Wang, Z., Palmer, A., Grattan, K. and Jackson, D., "Recent Progress in Optical Current Sensing techniques,"

Review of Scientific Instruments, Vol. 12, No. 2, pp. 5, April 1995.

Abstract:

This paper reviews recent developments in the field of current measurement which employ a wide range of optical and fiber optic techniques. Depending on the current sensing mechanisms involved and the sensing materials used, optical current sensors (OCSs) may be categorized into four main groups: (i) OCSs employing optical fiber as their sensing elements, (ii) OCSs using bulk glass to sense the current, (iii) OCSs using electro-optic hybrid sensing devices, and (iv) OCSs using magnetic field sensing devices. The operational modes of a variety of OCSs have been grouped and discussed, and several examples given. It can be seen that as a result of an intensive and wide ranging research effort using various approaches, substantial progress in the differing aspects of the optical current sensing techniques considered, such as the sensing material used, the configurations of sensing elements introduced, and the detection schemes adapted, has been achieved during the past years. An overall view of the field shows it to be as an active and exciting research area, highlighting several recently introduced and novel sensing materials and configurations which provide impressive results in this field of instrumentation. Examples of applications for the electric power industry are discussed more extensively.

OCT type: Magnetic concentrator

Power systems relevance: ** 
[138] Okonek, S.,

"Fiber-Optic Voltage and Current Sensors for Distribution Systems,"

EPRI TR-100291, Project WO4555, October, 1992.

Abstract:

This report describes the successful prototyping of fiber-optic-based current and voltage sensors for power distribution systems in the $15 \mathrm{kV}-35 \mathrm{kV}$ range. Use of such sensors promises to be more economical on an installed basis than conventional current and voltage transformers.

OCT type: Fiber

Power systems relevance:

[139] Papp, A. and Harms, H.,

"Magneto-optical Current Transformer. I. Principles II. Components III. Measurements," Applied Optics, Vol. 19, No. 22, pp. 3729-3734, November 15, 1980.

Abstract:

The principles of measuring currents in high-voltage lines by magneto-optical means are described. Particular attention is payed to using an optical fiber both as a transmission line and a measuring sensor. The influence of birefringence on the measuring signal is discussed.

OCT type: $\quad$ Multiple

Power systems relevance: ***

[140] Patterson, R.L., Rose, A.H., Tang, D. and Day, G.W., "A Fiber-optic Current Sensor for Aerospace Applications,", IEEE AES Systems Magazine, December , 1990.

OCT type: Fiber

Power systems relevance: * 
[141] Pease, J. and Tillet, J.,

"Optical PT's and CT's for Metering and Relaying,",

BPA Internal Publication, 1994.

Abstract: $\quad$ None

OCT iype: $\quad$ Bulk glass

Power systems relevance: ***

[142] Pelenc, Y.,

"Transoptics: Current Transformers Using Magneto-optic Effect for Very High Voltages," L'Electricien, Vol. 82, No. 2104, pp. 63-66, March, 1969, French.

Abstract:

The disadvantages of conventional current transformers when used to measure current at high voltages are described, and those of alternative devices are tabulated. The optical device selected as the best of these takes advantage of the Faraday effect in which the plane of polarization of a beam of light passing through a transparent medium is rotated by an amount proportional to the magnetic field and the path length. Polarized light is passed through a lead glass cylinder, around which is wound a coil carrying the current to be measured, through a second polarizer to a photo-electric device. The intensity of light received is then a direct measure of the current.

OCT type: $\quad$ Bulk glass (solenoid)

Power systems relevance: $* *$

[143] Pelenc, Y. and Bernard, G., "Measurement of ac and dc at Very High Voltage by the Faraday Effect Optical Transformer," MESUCORA International Conference 1973 Sessions 1-3, pp. 1.31-1.41, April 12-18, 1973.

Abstract:

Current measurement on high voltage networks by the use of the Faraday Effect is being considered as a solution to future problems in measurements. This paper considers in detail the electro-optical components of the proposed measurement equipment. A study is made of the luminous flux, transmission by the use of optical fibres, the source of light required, and the problem of optical compensation. The effects of fault conditions and the measurement of DC are considered. Finally the applicability of the technique to analogue-digital conversion is reviewed.

OCT type: $\quad$ Fiber

Power systems relevance: $* *$ 
[144] Petersen, A., "Portable Optical AC-current and Proposed DC-current Sensor for High-Voltage Applications,"

IEEE Transactions on Power Delivery, Vol. 10, No. 2, pp. 595-599, 1995.

Abstract:

The design and testing of a passive optical current sensor utilizing the Faraday effect is described. The system, being of the ring core sensor type, is portable and capable of being mounted on existing cables and power lines without disconnection. System performance regarding linearity, temperature dependence and the influence of current conductor displacement relative to the ring core are reported. A proper passive temperature compensation is tested and a scheme for optical measurement of de-current proposed.

OCT type: Clamp-on bulk glass

Power systems relevance: **

[145] Pistoni, N.C. and Martinelli, M., "Vibration-insensitive Fiber-optic Current Sensor," Optics Letters, Vol. 18, No. 4, pp. 314-316, February, 1993.

Abstract:

The measurement of the electric current with an optical fiber sensor can be made insensitive to external vibrations that act on the leading fiber by using a circuit involving a mirrored Faraday rotator and a highly twisted low-birefringence fiber. A description of the optical configuration as well as our first experimental results are presented. The circuit gives a passive compensation of the disturbances with a measured rejection of the order of $30 \mathrm{~dB}$ while maintaining the correct sensitivity to the measurement of the Faraday effect.

OCT type: Fiber

Power systems relevance: * 
[146] Qian, J.R. and Luksun, L.

"Current Sensors Using Highly-birefringent Bow-Tie Fibers,"

4th International Conference on Optical Fiber Sensors, Tokyo, Japan, 1986.

Abstract:

none

OCT type: Fiber

Power systems relevance: **

[147] Rajkumar, N., Kumar, V.J., and Sankaran, P., "Fiber Sensor for the Simultaneous Measurement of Current and Voltage in a High-Voltage System,"

Applied Optics, Vol. 32, No. 7, pp. 1225-1226, March 1, 1993.

Abstract:

A sensor employing a single monomode low-birefringence fiber, excited with a 632.8-nm He-Ne laser, has been developed for the simultaneous measurement of current and voltage in an energy system. The piezoelectric effect for the voltage and the magnetic stress for the current are utilized. The current and voltage signals are separated at the detector end by suitable self-tracking tuned filters. Experimental results from a laboratory model demonstrate the feasibility of the sensor for field application in high-voltage systems.

OCT type: Multiple

Power systems relevance: $* *$ 
[148] Rao, M., Reddy C. N., Vanugopal, M. and Murthy, N.S.N.,

"Current Measurements in EHV Lines Using Lasers,"

Journal of the Institution of Engineers (India), Vol. 59, pp. 287-291, April, 1979.

Abstract:

The shortcomings of conventional current transformers for measuring current in extra high voltage transmission lines are sought to be overcome using laser beams. Of the two methods: (a) the tracer system and (b) the Faraday effect technique, the latter is found to be more suitable and is chosen for this purpose. The results of experimental investigations using this method for measuring current are reported.

OCT type: $\quad$ Multiple

Power systems relevance: **

[149] Rashleigh, S.C. and Ulrich, R.,

"Magneto-optic Current Sensing with Birefringent Fibers,"

Applied Physics Letters, Vol. 34, No. 11, pp. 768-770, June, 1979.

Abstract:

To measure currents on high-voltage lines, the Faraday rotation is used in a single-model optical fiber encircling the conductor. Disturbing linear birefringence is suppressed by twisting the fiber. With approximately $10 \mathrm{~m}$ of fiber, coiled with a $3-\mathrm{cm}$ radius, the authors obtain $0.25 \mathrm{mrad} / \mathrm{A}$ polarization rotation, permitting measurement of currents of $0.2 \mathrm{~A}$ to $2000 \mathrm{~A}$.

OCT type: $\quad$ Fiber

Power systems relevance: * *

[150] Rochford, K.B., Day, G.W., and Forman, P.R.,

"Polarization Dependence of Response Functions in 3x3 Sagnac Optical Fiber Current Sensors," Journal of Lightwave technology, Vol. 12,No. 8, pp. 1504-1510, August, 1994.

OCT type: $\quad$ Fiber

Power systems relevance: * 
[151] Rochford, K.B., Day, G.W., and Forman, P.R., "Polarization Dependence of Response Functions in 3x3 Sagnac Optical Fiber Current Sensors," 9th International Optical Fibre Sensors Conference, Florence, Italy, 1993.

Abstract:

The response functions of an ideal Sagnac optical fiber current sensor based on a $3 \times 3$ coupler fundamentally depend on the polarization state of light entering the coupler, even for a zero birefringence system. The desired response functions, sinusoids separated by 120 degree phase shifts, are obtained only for circularly polarized light. The response functions for linearly polarized and depolarized inputs are sinusoids separated by 180 degrees, and yield only zero-slope small-signal responses; in addition, two outputs are degenerate, so the response is similar to that observed in $2 \times 2$ systems. Thus, $3 \times 3$ couplers offer no advantage over $2 \times 2$ systems for linearly polarized light. This result increases system complexity in that polarization control optics are required to supply the proper polarization, even for an ideal, zero-birefringence system.

OCT type: Fiber

Power systems relevance: *

[152] Rochford, K.B., Rose, A.H., Deeter, M.N. and Day, G.W., "Faraday Effect Current Sensor with Improved Sensitivity Bandwidth Product," Optics Letters, Vol. 19, No. 22, pp 1903-1905, November, 1994,.

Abstract:

OCT type: $\quad$ Fiber

Power systems relevance: * 
[153] Rogers, A.J.,

"Optical Technique for Measurement of Current at High Voltage,"

Proceedings of the Institution of Electrical Engineers, Vol. 120, No. 2, pp. 261-267, February, 1973.

Abstract:

Consideration is given to the design of an optical device for the measurement of current at high voltage based on the Faraday magneto-optic effect in flint glass. A laser beam directed upward from the ground passes through the free atmosphere to interrogate a passive transducer situated on the high-voltage line. The beam is then reflected down to a ground-based detector system. The investigation has been directed, in the first instance, towards the provision of a versatile research tool for the analysis of disturbed-line conditions, although, ultimately, such an arrangement could obviate the necessity for the expensive and bulky insulation found in conventional current transformers. This is particularly relevant in view of the trend towards high transmission voltages. The appropriate design features are considered in some detail. Their implementation in a prototype device is also considered. The bandwidth of the prototype device was from direct current to $2 \mathrm{MHz}$, and its dynamic range for less than $5 \%$ nonlinearity.

OCT type: Bulk glass

Power systems relevance: $* * *$

[154] Rogers, A.J.,

"Optical Measurement of Current and Voltage on Power Systems,"

Electric Power Applications, Vol. 2, No. 4, pp. 120-124, August, 1979.

OCT type: $\quad$ Multiple

Power systems relevance: $* *$ 
[155] Rogers, A.,

"Measurement Using Fibre Optics,"

New Electronics, Vol. 14, No. 21, October 27, 1981.

Abstract:

Discusses the growing importance of optical fibres for use as measurement sensors. Applications covered include the 'break-point' sensor, band-loss sensor, flow meter and electric current sensor. Topics such as input power variations and practical problems are dealt with, and integrated opto-electronics is briefly reviewed.

OCT type: $\quad$ Fiber

Power systems relevance: *

[156] Rogers, A.J.,

"A Vibration-insensitive Optical-fibre Current Sensor,"

SPIE Fibre Optics, Vol. 630, 1986.

Abstract:

Electric current may be measured very conveniently by utilizing the Faraday magneto-optic effect in a monomode fiber looped around a conductor. Devices based on this idea presently suffer from a sensitivity to vibration. This paper explains the nature of the vibrational sensitivity, and proposes a number of techniques which could reduce it to acceptable levels.

OCT type: $\quad$ Fiber

Power systems relevance: $* *$

[157] Rogers, A.,

"Optical Measurements of Power-System Quantities,"

Electronics \& Power, February, 1986.

Abstract:

The adoption of optical-fiber signaling by the electricity supply industry has left the way open for a wide range of measurement techniques to be adopted using those fibers. But the demands for equipment are out stripping optoelectronic technology.

OCT type: Multiple

Power systems relevance: *** 
[158] Rogers, A.J.,

"Optical-fibre Current Measurement,"

International Journal of Optoelectronics, Vol. 3, No. 5, pp. 391-407, 1988.

Abstract:

Passive optical-fiber-current measurement devices offer technical and economic advantages for power-system use. Methods which have been examined for implementing such devices are reviewed and the present position is summarized, with theoretical justification. Prospects for the future are considered.

OCT type: Fiber

Power systems relevance: *

[159] Rogers, A.J., Xu, J., and Yao, J.,

"Vibration Immunity for Optical-Fiber Current Measurement,"

Journal of Lightwave Technology, Vol. 13, No. 7, pp. 1371-1377, July, 1995 .

Abstract:

Optical-fiber measurements of electric current can be rendered immune from the effects of environmental vibration by utilizing the non-reciprocity of the Faraday effect in an arrangement which propagates light simultaneously in the two directions around a fiber loop enclosing an electric current. The system is compared with a back-reflection arrangement. Temperature variations are also suppressed.

OCT type: Fiber

Power systems relevance: *

[160] Rogers, A.J.,

"Optical Methods for Measurement of Voltage and Current on Power Systems,"

Optics and Laser Technology, 9, 1997.

OCT type: $\quad$ Multiple

Power systems relevance: $* *$ 
[161] Rose, A.H., Deeter, M.N, and Day, G.W.,

"Submicroampere-per-root-hertz Current Sensor-based on the Faraday-effect in Ga:YIG," Optics Letters, Vol. 18, No. 17, pp. 1471-1473, September 1, 1999.

Abstract:

We demonstrate an optical current sensor that is based on the Faraday effect in gallium-substituted yttrium iron garnet and has a measured sensitivity of approximately 3 degrees/A, a noise-equivalent current of approximately $220 \mathrm{nA} /$ square-root $\mathrm{Hz}$, and a $-3 \mathrm{~dB}$ bandwidth of approximately $2.6 \mathrm{MHz}$. The bandwidth-sensitivity product is a factor of approximately 10 greater than that of an all-silica-fiber current sensor with the same diameter.

OCT type: Thin film

Power systems relevance: *

[162] Rose, A.H. Ren, Z.B. and Day, G.W, "Twisting and Annealing Optical Fiber for Current Sensors," Journal of Lightwave Technology, Vol. 14, No. 11, pp. 2492-2498, November, 1996.

Abstract:

We demonstrate that twisting a fiber a few turns per meter before it is annealed largely eliminates the residual linear birefringence. This dramatically improves the yield of annealed coils used for current sensing and makes it possible to use fibers that previously had large residual linear birefringence. Twisting the fiber is effective because the residual birefringence, associated with core ellipticity, is reduced to near zero by twisting. A theoretical model of the twisted and annealed fiber current sensor is compared to experimental data, We also show good temperature stability for a sensor made with this new technique.

OCT type: Fiber

Power systems relevance: * 
[163] Rzewuski, M.N. and Tarnawecky, M.Z.,

"Unconventional Methods of Current Detection and Measurement in EHV and UHV

Transmission Systems (Use of Optical and E.M. Transformers),"

IEEE Transactions on Instrumentation and Measurement, Vol. IM-24, No. 1, pp. 43-51, March, 1975.

Abstract:

The use of optical and electromagnetic current transformers for protection and measurement in EHV transmission systems is outlined along with salient specifications imposed by diversification of present-day applications. Basic principles of operation and typical applications of optical and electromagnetic current transformers are presented.

OCT type: Bulk glass

Power systems relevance: $* * *$

[164] Sawa, T., Kurosawa, K., Kaminishi, T., and Yokota, T., "Development of Optical Instrument Transformers,"

IEEE Transactions on Power Delivery, Vol. 5, No. 2, pp. 884-891, 1990.

Abstract:

The optical instrument transformer is a current and voltage measuring system based on Faraday and Pockels effects, whose principles differ from those of conventional industrial transformers. In principle, this transformer is excellent in such aspects as control of electromagnetic induction noise, rationalization of electrical insulation, and extension of dynamic ranges and frequency bands. By making use of such excellent properties, it is possible to achieve higher performance, higher compactness, and higher reliability of instrument transformers. This paper deals with the designing, assembling, and testing results of a prototype of an optical current transformer (CT) and that of a voltage dividing-type voltage transformer (PD). The optical CT and PD were developed to be applicable to 3-phase-enclosed-type $300 \mathrm{kV}$ gas-insulated switchgear (GIS) and air-insulated $168 \mathrm{kV}$ substation systems. Test results for the newly developed optical CT and PD showed that their basic properties conform with JEC 1201.

OCT type: Bulk glass

Power systems relevance: $* * *$

[165] Scozzafava, T.,

"Faraday Effect Instrument Transformers for E.H.V. Power Plants," Energia Elettrica, Vol. 47, No. 10, pp. 655-664, 1970, Italian.

Power systems relevance: $* *$ 
[166] Shamray-Bertaud, P. and Carome, E.F., "Lower Cost Fiber Optic Current Sensor for Electric Power Transmission and Distribution Systems,"

EPRI: Optical Sensing in Utility Applications, San Francisco, USA, May 14-15, 1991.

Abstract:None

OCT type: Magnetic reed

Power systems relevance: ***

[167] Shafir, E., Shaked, N., Ben-Kish, A. and Tur, M., "The Response of Faraday-Effect-Fiber-Optic Current Sensors to Non-centered Currents," $9^{\text {th }}$ International Optical Fiber Sensors Conference, Florence, Italy, 1993.

Abstract:

Experimental evidence and theoretical investigations (based on the presence of linear birefringence) are presented for the dependence of the output of a Faraday rotation fiber-optic current sensor on the location of the electrical conductor.

OCT type: Fiber

Power systems relevance: *

[168] Short, S.X., De Arruda, J.U., Tselikov, A.A., and Blake, J., "Stable Scale Factor Performance of an In-line Sagnac Interferometer Current Sensor," 12th International Conference on Optical Fiber Sensors, Williamsburg, USA, October 28-31, 1997.

Abstract:None

OCT type: Fiber

Power systems relevance: * 
[169] Simmon, E.D., Rose, A.H., and FitzPatrick, G.J., "An Optical Current Transducer for Calibration Studies,"

8th International Symposium on High Voltage Engineering, Yokohama, Japan, August, 23-27, 1993.

Abstract:

Optical current transducers(OCTs) are well-suited for current measurements in high voltage applications because they offer advantages over conventional oil-filled current transformers such as greater immunity from electromagnetic interference (EMI), intrinsic safety, and wide dynamic range. This paper describes an OCT designed and built at the National Institute of Standards and Technology (NIST) for in the development of calibration methods for OCTs for power system applications. The design and operating characteristics of the NIST OCT are described and the results of tests for sensitivity, linearity, and dynamic range are reported. Some of the sources of measurement error are discussed.

OCT type: Fiber

Power systems relevance: **

[170] Smith, A. M.,

"Optical Fiber Current Measurement Device at a Generating Station,"

Proceedings of the Society of Photo-Optical Instrumentation Engineers, Vol., 236, pp. 352-357, 1980.

Abstract: None

OCT type: Fiber

Power systems relevance: $* * *$ 
[171] Song, J., McLaren, P.G., Thomson, D.L. and Middleton, R.L.,

"A Prototype Clamp-on Magnetoical Current transducer for Power-system Metering and Relaying,"

IEEE Transactions on Power Delivery, Vol. 10, No. 4, pp. 1764-1770, 1995.

Abstract:

A new type of Faraday effect based magneto-optical current transducer (MOCT) has been developed. This paper presents the theoretical background, engineering design, and test results of this clamp-on MOCT. The sensor consists of two separate clamp-on parts. This design avoids the need to break the current carrying circuit in order to have the conductor enclosed by the optical path. A feedback scheme has been designed to stabilize the light source. The MOCT has two output stages, $1 \mathrm{kA}$ and $20 \mathrm{kA}$, so that it can provide current signals for both power system metering and relaying devices. The theoretical background of maintaining the light travelling through the glass prism to be linearly polarized and the analysis on the effects of dielectric and metal reflections on the linearly polarized light is presented in the appendix.

OCT type: $\quad$ Clamp-on, Bulk glass

Power systems relevance: $* * *$ 
[172] Stalsberg, K., Au, W., Strandjord, L., Goettsche ,R., El-Wailly,T., Sanders, G., Blake, J., Demko, J., and Chilton, W.,

"Fiber Optic Current Sensor and Multi-Application Data Acquisition and Analysis System," Proceedings of the Georgia Tech Fault and Disturbance Analysis Conference, 1998.

Abstract:

This paper describes a newly developed Fiber Optic Current Sensor (FOCS) that provides significantly improved current sensing capability over existing current transformers (CT). Also described is the data acquisition and analysis system used to develop advanced power system monitoring applications incorporating the FOCS. The new current sensing capability includes improved accuracy, linearity, sensing bandwidth, and dynamic range; all contributing to improved measurement, protection, control, and analysis for power generation. Additionally, the FOCS bring benefits of inherent isolation and ease of installation. The data acquisition and analysis system is a modular, embedded-PC, open development platform designed for rapid application development. High-performance data acquisition fully supports the FOCS sensing capabilities while allowing synchronous data collection from the installed sensor base. FOCS and data acquisition/analysis system prototypes have been installed on a 134 MVA generator at Arizona Public Service Company - Cholla Power Plant. Work is underway to assess installed FOCS performance and to detect phenomena from the generator phase and exciter current signatures that relate to the mechanical operation of the turbine-generator.

OCT type: $\quad$ Fiber

Power systems relevance: $* * *$ 
[173] Takahashi, M.,Noda, H.,Terai, K.,Ikuta, S.,Mizutani, Y.,Yokota, T., Kaminishi, T., and Tamagawa, T.,

"Optical Current Transformer for Gas Insulated Switchgear Using Silica Optical Fiber, "

IEEE Transactions on Power Delivery, Vol. 12, No. 4, pp. 1422-1427, 1997.

Abstract:

The high accuracy optical current transformer (optical CT) for the gas insulated switchgear (GIS) using $\mathrm{R}$ silica optical fiber has been developed. The linear birefringence was reduced by twisting the newly developed double coated optical fiber. The current of up to $8000 \mathrm{~A}$ was measured within electric noise error of $3.8 \mathrm{~A}_{\mathrm{rms}}$ and a sensitivity change of $0.4 \%$ was observed over the temperature range from -20 to $90{ }^{\circ} \mathrm{C}$. This change corresponds to the temperature dependence of the Verdet constant of silica. When the vibrating acceleration of $8 \mathrm{G}$ was applied by the gas circuit breaker motion, no signals were distinguished from the background noise level of $3.8 \mathrm{~A}_{\mathrm{rms}}$ The long term test was carried out and the accuracy of the measurements was kept to within $0.15 \%$ during 8 hours. This is the first practical optical CT to satisfy all requirements for GIS.

OCT type: $\quad$ Fiber

Power systems relevance: $* * *$

[174] Tang, D., Rose, A.H., Day, G.W. and Etzel, S.M., "Annealing of Linear Birefringence in Single-mode Fiber Coils: Application to Optical Fiber Current Sensors,"

Journal of Lightwave Technology, Vol. 9, No. 8, pp. 1031-1037, August, 1991.

Abstract:

Annealing procedures that greatly reduce linear birefringence in single-mode fiber coils are described in detail. These procedures have been successfully applied to coils ranging from $5 \mathrm{~mm}$ to $10 \mathrm{~cm}$ in diameter and up to 200 or more turns. They involve temperature cycles that last 3-4 days and reach maximum temperatures of about 850 degrees $C$. The residual birefringence and induced loss are minimized by proper selection of fiber. The primary application of these coils is optical fiber current sensors, where they yield small sensors that are more stable than those achieved by other techniques. A current sensor with a temperature stability of $+8.4 \times 10^{-5} / \mathrm{K}$ over the range from $-75{ }^{\circ} \mathrm{C}$ to $+145{ }^{\circ} \mathrm{C}$ has been demonstrated. This is approximately $20 \%$ greater than the temperature dependence of the Verdet constant. Packaging degrades the stability, but a packaged sensor coil with a temperature stability of about $+1.6 \times 10^{-4} / \mathrm{K}$ over the range from $-20{ }^{\circ} \mathrm{C}$ to $+120{ }^{\circ} \mathrm{C}$ has also been demonstrated.

OCT type: Fiber

Power systems relevance: * 
[175] Tang, D., Rose, A.H., and Day, G.W.,

"Optical Fiber Current Sensors with Temperature Stabilities near the Material Limit,"

Proceedings of the 7th OFS Conference, Sydney, Australia, pp. 77-80, December 2-6, 1990.

Abstract:

We describe an optical fiber current sensor with a normalized temperature coefficient of $+8.4 \mathrm{x}$ $10^{-6} / \mathrm{K}$ over the range from $-75^{\circ} \mathrm{C}$ to $+145^{\circ} \mathrm{C}$. This is within $20 \%$ of the limit set by the temperature dependence of the Verdet constant measured in bulk silica. Packaging of the sensor coil degrades its stability, but a fully packaged coil with a stability of $+1.7 \times 10^{-4} / \mathrm{K}$ over the range from $-30{ }^{\circ} \mathrm{C}$ to $+125^{\circ} \mathrm{C}$ has also been demonstrated.

OCT type: Fiber

Power systems relevance: *

[176] Taniuchi, T., Kamada, O., Hayashi, Y., Takiuchi, S., Toda, K., Kawabata, A. and Tsujimoto, Y.,

"Fiber Optic Current and Voltage Meters,"

Natl Tech Rep Matsushita Electr Ind, Vol. 29, No. 5, pp. 70-80.

Abstract:

OCT type: $\quad$ Fiber

Power systems relevance: ** 
[177] Tawara, H.,

"Measurements of Pulsed Current and Magnetic Field by the Faraday Effect,"

Japanese Journal of Applied Physics, Vol. 7, No. 10, pp. 1254-1258, October, 1968.

Abstract:

Pulsed magnetic field up to $20 \mathrm{kG}$ was measured by the Faraday effect. The present optical measuring method, though rather simple arrangement, in which the angle between polarizer and analyzer axes is set to $-\pi / 4$, can make a direct observation possible on accurate waveform and direction of pulsed magnetic field and current with a duration of a few microseconds. Also noises caused by pulsed current source can be eliminated or reduced by using the optical fibers with which the Faraday probe is coupled to the light detector placed a few meters apart from pulsed current source. Some applications of the present method are simply described.

OCT type:

Power systems relevance: *

[178] Terai, K., Takahashi, M., Ikuta, S., Mizutani, Y., Noda, H. And Kaminishi, T., "Practical Optical Fiber Current Transformer for Gas Insulated Switchgear," 12th International Conference on Optical Fiber Sensors, Williamsburg, USA, October 28-31, 1997.

Abstract:

Application of optical current transformer (Optical CT) to the electric power systems is a considerable interest. The optical CT has attractive features compared to a conventional current transformer consisting of an iron core and copper winding, such as no saturation effects, excellent electric isolation and no requirement of flammable materials. Using optical fiber as the Faraday medium makes the optical CT simple and low-cost. Here we present practical optical CT using moderate twisted silica optical fiber with temperature-independent coating. It makes use of the Faraday effect and a current is measured by the polarimetric method. The optical CT satisfied all requirements for the gas insulated switchgear (GIS).

OCT type: Fiber

Power systems relevance: $* * *$ 
[179] Todd, D. and Carter, C.,

"Sumitomo Fiber Optic Voltage and Current Sensors Evaluation,"

Workshop on the Role of Optical Sensors and Power Systems Voltage and Current

Measurements, 1987.

Abstract:

Sumitomo Electric has developed a unique fiber-optic voltmeter and magnetic field meter by integrating its fiber-optic technology and bismuth silicon oxide (BSO) signal crystal growth technology. Conductor current is determined from the measurement of the surrounding magnetic field, and voltage is determined from an electric field measurement. Two voltage sensors and a current sensor were evaluated at the Tennessee Valley Authority. Results indicate that at power system frequencies $(60 \mathrm{~Hz})$ the sensors have a linear input/output characteristics, introduced no significant a shift, and faithfully reproduce typical input waveforms.

OCT type: Magnetic concentrator

Power systems relevance: ***

[180] Tokoro, K., Harumoto, Y., Yamamoto, H., Yoshida, Y., Mukae, H., Ohno, Y., Shimada, M. and Ida, Y.,

"Development of Electronic Potential and Current Transducers Suitable for Gas Insulated Switchgear and Adequate for Application to Substation Digital Control System,"

IEEE Transactions on Power Apparatus and Systems, Vol. PAS-101, No. 10, pp. 3967-3976, 1982.

Abstract:

OCT type:

Power systems relevance: $* * *$ 
[181] Ulmer, Jr., E.A.,

"A High-Accuracy Optical Current Transducer for Electric Power Systems,"

IEEE Transactions on Power Delivery, Vol. 5, No. 2, pp. 892-898, April, 1990.

Abstract:

This paper reports for the first time on an optical current transducer employing a new, simple, technique to measure electric current. The technique is based on a fundamental analysis of the Faraday effect. An optical current transducer (OCT) has been designed which overcomes the disturbing effect of temperature on the glass sensing element. By aligning the transmission axis of the polarizer at a specific angles, the OCT's output is shown to be independent of temperature. High accuracy measurements are thereby possible over a wide range of temperatures. Two practical OCT designs for extra-high voltage power systems are compared.

OCT type: $\quad$ Bulk glass

Power systems relevance: $* *$

[182] van den Tempel, C.M.M.,

"Model of a New Temperature-compensated Optical Current Sensor Using $\mathrm{Bi}_{12} \mathrm{SiO}_{20}$," Applied Optics, Vol. 27, No. 13, pp. 4869-4874, September, 1993.

Abstract:

A new optical bulk current sensor is presented with $\mathrm{Bi}_{12} \mathrm{SiO}_{20}$ as a sensing crystal. Through the use of a mirror in the setup and the reciprocity of the optical activity of $\mathrm{Bi}_{12} \mathrm{SiO}_{20}$, the sensor becomes insensitive to intrinsic linear birefringence and birefringence that is due to the enclosure of the crystal. Therefore the sensor is also insensitive to temperature, which affects the total linear birefringence. By making a computer model of the $\mathrm{Bi}_{12} \mathrm{SiO}_{20}$ sensor, it was proved that the output signal of the sensor, which has a sinusoidal response, has a maximum relative error of $0.05 \%$, apart from the variation of the Verdet constant, for a temperature change of approximately $100^{\circ} \mathrm{C}$.

OCT type: $\quad$ Bulk glass

Power systems relevance: * 
[183] Veeser, L.R. and Day, G.W., "Faraday Effect Current Sensing using a Sagnac Interferometer with a 3x3 Coupler," $7^{\text {th }}$ Optical Fiber Sensors Conference, Sydney, Australia, December 2-6, 1990.

Abstract:

We demonstrate a fiber optic current sensor based on a Sagnac interferometer with a $3 \times 3$ fiber coupler. Compared to the more common Sagnac interferometer with a $2 \times 2$ coupler, this design offers the additional benefits of a greater response for small signals and the unambiguous interpretation of signals that exceed the period of the response function.

OCT type: $\quad$ Fiber

Power systems relevance: *

[184] Wang, Z.P. and Zhang, S.Q. and Zhang, L.B., "Recent Advances in Optical Current-Sensing Techniques," Sensors and Actuators A-Physical, Vol. 50, No. 3, September, 1995.

Abstract:

The Faraday effect is becoming widely used as an optical method of measuring electric current or magnetic field. It is particularly advantageous where the measurements must be made at high voltage or in the presence of electromagnetic interference, and where speed or stability are considerations. In this paper, the present state of research into Faraday effect current sensors is outlined, eight possible approaches for overcoming the problems associated with the linear birefringence inside the fibres of optical current sensors are simply introduced, recent advances in this area are reviewed, and possible prospects are considered.

OCT type: $\quad$ Fiber

Power systems relevance: *

[185] Willsch, M., Bosselmann, T., and Wollenhaupt, M.,

New Principle for the Extension of the Measuring Range of Fiber Optic Current Sensors," 12th International Conference on Optical Fiber Sensors, Williamsburg, USA, October 28-31, 1997.

Abstract:None

Power systems relevance: $* *$ 
[186] Willsch, T., Bosselmann, T. and Bretschneider, M.,

"Investigation of the Vibration Sensitivity of Different Annealed Fiber Optic Current

Transformers,"

12th International Conference Optical Fiber Sensors, Williamsburg, USA, October 28-31, 1997.

Abstract:None

OCT type: $\quad$ Fiber

Power systems relevance: $* *$

[187] Woolsey, G.A., Fisher, N.E. and Jackson, D.A.,

"Tuning a Bulk-glass Optical Current Sensor by Controlling Conditions External to its Reflecting Surfaces,"

Sensors and Actuators A-Physical, Vol. 63, No. 1, pp. 6, September, 1997.

Abstract:

In a bulk-glass triangular Faraday current sensor, the stringent conditions required to provide critical-angle reflection at each reflecting surface are difficult to achieve. High tolerances for both the optical geometry of the sensor and the wavelength of the laser source are required. Here we present a method of essentially tuning the sensor for optimum operation by matching the angle of reflection at each surface to the wavelength of the laser source. This is done by controlling the gaseous environment external to each of the reflecting surfaces. The technique is demonstrated using sulphur hexafluoride $\left(\mathrm{SF}_{6}\right)$, which has the advantage of a relatively large refractive index.

OCT type: Bulk glass

Power systems relevance: * 
[188] Yamamoto, M., Ifukube, A., Murata, Y. and Hashimoto, M., "Development of Fault Detector for 33-KV Ungrounded Power-line," Electrical Engineering in Japan, Vol. 115, No. 4, pp. 11, 1995.

Abstract:

A fault section detection system is being developed for $33-\mathrm{kV}$ ungrounded power line. The fault section is obtained from the relation of two point zero-phase currents on power line. This fault detector is composed of optical current sensors and the processing unit and solar battery system. The optical current sensor consists of a Faraday cell and a porcelain bushing. Zero phase current on the processing unit is obtained through a three-phase composer with auto gain control and residual current eliminator. This fault detector has the ability of $0.15 \mathrm{~A}$ zero-phase current detection fault factory test; in field tests, this fault detector detects ground fault.

OCT type: $\quad$ Magnetic concentrator

Power systems relevance: $* * *$

[189] Yamagata, Y. ,Oshi, T., Katsukawa, H., Kato, S., Sakurai, Y., Kirkham, H. and Johnston, A.R.,

"Development of Optical Current Transformers and Application to Fault Location Systems for Substations,"

IEEE Transactions on Power Delivery, Vol. 8, No. 3, pp. 866-873, 1993.

Abstract:

OCT type: Magnetic concentrator

Power systems relevance: $* * *$ 
[190] Yi, B., Cruden, A. McDonald, J.R., and Andinovic, I.,

"A Novel Bulk-Glass Optical Current Transducer Having an Adjustable Multi-ring Optical Path," IEEE Instrumentation and Measurement Technology Conference, Ottawa, Canada, May 19-21, 1997.

Abstract:

This paper describes a new design of bulk type Faraday effect based optical current transducer. The sensing element is a four-piece bulk optic structure which enables the polarized light to circulate around the conductor a number of times and increases the sensitivity several times. The design makes for ease of manufacturing and alignment. The number of closed optical paths can be changed easily by adjusting the incident point of light. The principle of the design is described and simulation and experimental results are presented.

OCT type: $\quad$ Bulk glass

Power systems relevance: *

[191] Yoshino, T. and Gojyuki, M. and Takahashi, Y. and Shimoyama, T., "Single Glass Block Faraday Effect Current Sensor with Homogeneous Isotropic Closed Optical Circuit,"

Applied Optics, Vol. 36, No. 22, August 1, 1997.

Abstract:

OCT type: Bulk glass

Power systems relevance: * 
[192] Yoshida, Y.,Kawazoe, S., Ibuki, K., Yamada, K., and Ochi, N., "New fault Locating System for Air-insulated Substations Using Optical Current Detector," IEEE Transactions on Power Delivery, Vol. 7, No. 4, pp. 1805-1812, October, 1992.

\section{Abstract:}

This paper deals with a newly developed fault locating system. This fault locating system helps to shorten the time required for restoration of service after the occurrence of a busbar fault in an air-insulated distribution substation. Recent optical and electronic technologies allow highly accurate and compact fault locating systems, which consists of optical current detectors using Faraday effect and a fault locating processor employing digital data processing technique. The fault location is made by discriminating the direction of zero-sequence currents. Through various tests and field operations, it has been confirmed that the system has sufficient performance for practical application.

OCT type: Magnetic concentrator

Power systems relevance: $* * *$

[193] Yu, T., Li, Q., Chen, R. and Yan, J.

"Magnet Sensitive Optical Fiber and its Application in Current Sensor System," SPIE, O/E Fibers, 1991.

OCT type: $\quad$ Fiber

Power systems relevance: * 
[194] Yu, A. and Siddiqui, A.S.,

"Practical Sagnac Interferometer Based Fiber Optic Current Sensor,"

IEE Proceedings-Optoelectronics, Vol. 141,No. 4, pp. 8, August, 1994.

Abstract:

A theoretical and experimental investigation of a practical new Sagnac interferometric optical fiber current sensor using a 3 x 3 fiber coupler is presented. A simple analytical expression for the output response of the sensor has been derived in the presence of bend-induced linear birefringence and twist-induced circular birefringence in the fibre sensing coil. This represents the first analytic formulation for this type of current sensor. The effects of the bend-induced linear birefringence and twist-induced circular birefringence on the phase bias and scale factor have been analyzed in detail. Numerical simulation was also carried out to study the effect of various disturbances and imperfections such as intrinsic linear birefringence and localized birefringence in the sensing fiber. It is shown that our proposed structure minimizes the effects of variations, as might be caused by temperature changes, for example, in the bend-induced linear birefringence, on the sensor stability. Preliminary experimental results show good temperature stability without the use of any passive or active compensation arrangement.

OCT type: $\quad$ Fiber

Power systems relevance: *

[195] Yu, A. and Siddiqui, A.S.

"A Theoretical and Experimental Investigation of a Practicable Fibre Optic Current Sensor Using Sagnac Interferometer,"

9th International Optical Fiber Sensors Conference, Florence, Italy, pp. 289-292, March, 1993.

Abstract:None

OCT type: Fiber

Power systems relevance: * 
[196] Zhang, W., Ning, Y.N., Palmer, A.W., and Grattan, K.T., "Effect of Coupling Condition on Vibration-induced Noise in Fiber Lead Used in an Optical Current Measurement System,"

Review of Scientific Instruments, Vol. 67, No. 8, August, 1996.

Abstract:

When using a multimode fiber lead in an optical current measurement system, the optical power in the guided modes is often determined by the coupling conditions at the input end of the fiber. If only the skew rays are excited in the fiber lead-under appropriate coupling conditions the vibration induced noise normally experienced in the fiber lead in such an optical current measurement system can be effectively suppressed, especially when a low coherence source and a long length of multimode fiber is used. The experimental conditions for this are considered and discussed in this article.

OCT type: Bulk glass

Power systems relevance: *

[197] Zhang, W., Ning, Y.N., Zhang, Z.P., Grattan, K.T.V., and Palmer, A.W, "Optimisation of Signal-to-noise Ratio in an Optical Current Measurement System Using Different Detection Schemes,"

IEE Proceedings-Science Measurement and Technology, Vol. 144, No. 4, pp. 6, 1997.

\section{Abstract:}

The comparative performance of two alternative detection schemes used in an optical current measurement system are stimulated and theoretically analyzed. An appropriate experimental arrangement is constructed to measure and compare the signal-to-noise $(\mathrm{S} / \mathrm{N})$ ratio obtained for these two detection schemes under conditions of the same level of noise being induced. Both simulated and experimental results show that the sensitivity and the $\mathrm{S} / \mathrm{N}$ ratio of an optical current measurement system varies with the changing of the detection scheme and the cross-polarization angle between the polarizer and analyzer. The highest sensitivity and the largest signal-to-noise ratio are obtained when using differential detection and a 45 degrees cross-polarization angle. These positive results suggest that such systems may find wider application in current sensing.

OCT type: Bulk glass

Power systems relevance: * 
[198] Zhang, W., Ning, Y.N., Grattan, K.T., and Palmer, A.W., "Analysis of the Effect of Vibration-Induced Noise in Different Fibre Leads used in an Optical Current-Measurement System,"

Sensors and Actuators A-Physical, Vol. 63, No. 2, pp. 6, October, 1997.

Abstract:

The noise induced by environmental perturbations, such as vibration in fiber leads, degrades the performance of an optical current-measurement system, and should be suppressed.

Vibration-induced noise in three types of fiber leads, single- mode, highly birefringent, and multimode fiber, has been measured when used in such an optical current-measurement system, and the effect quantified and discussed. The results have shown that vibration-induced noise may be suppressed in highly birefringent fiber by choosing carefully the input angle of a linearly polarized beam or by using a low-coherence source in the sensor. The noise observed can be effectively eliminated by employing a long length of multimode fibre and a low-coherence source, combined with appropriate coupling conditions.

OCT type: $\quad$ Fiber

Power systems relevance: * 


\section{Patents}

[P1] Abe, M., Mase, S, Kozuka, Y. (Assignee: NGK Insulators, Ltd.), "Method and apparatus for optically measuring electric current and/or magnetic field," U.S. Patent No. 4,956,607, September, 1990.

[P2] Adolfsson, M., Brogardh, T. (Assignee: Asea Aktiebolag) "Optical fiber measuring devices," U.S. Patent No. 4,547,729, October, 1985.

[P3] Arditty, H., Rollin, M., ( Assignee: Thomson-CSF), "Optical fibre interferometric electric current measuring device," U.S. Patent No. 4,542,338, September 17, 1985.

[P4] Asars, J A. (Assignee: Westinghouse Electric Corp.), "Electronic circuitry with self-calibrating feedback for use with an optical current sensor," U.S. Patent No. 4,540,937, September, 1985.

[P5] Belleville, C. Van Neste, R., Caron, S., Houle, A.C. , Thibault, P. (Assignee: Citeq ), "Optical interferometric current sensor and method using a single mode birefringent waveguide and a pseudo-depolarizer for measuring electrical current," U.S. Patent No. 5,587,791, Dec. 1996.

[P6] Blake, J. N. ( Assignee: The Texas A\&M University System) "Fiber Optics apparatus and method for accurate current sensing," U.S. Patent No. 5,696,858, December,1997.

[P7] Brandle, H. (Otelfingen, CH), Stierlin, Roland ( Assignee: Asea Brown Boveri Ltd) "Rugged fiber-optical current sensor based on the Faraday effect," U.S. Patent No. 5,136,235, August, 1992.

[P8] Chen, C.-l., Asars, J. A, Vaerewyck, E. G. (Assignee: Westinghouse Electric Corp.), "Temperature stabilized Faraday rotator current sensor by thermal mechanical means," U.S. Patent No. 4,612,500, September 1986.

[P9] Clarke, I..G.(Assignee: The University of Sydney) "Current sensor using a Sagnac interferometer and spun, single mode birefringent optical fiber to detect current via the Faraday effect," U.S. Patent No. 5,677,622, Oct. 1997.

[P10] Cruden, A.J., McDonald, J. R., Andonovic, I. Allan, K., Porrelli, R. A. (Assignee: Instrument Transformers Limited), "Electric current measurement," U.S. Patent No. 5,486,754, January 1996.

[P11] Dawson, J. W., MacDougall, T. W. ( Assignee: Minnesota Mining and Manufacturing Company) "Verdet constant temperature-compensated current sensor," U.S. Patent No. 5,780,847, July, 1998 .

[P12] Doerfler, R. W., Power, T. G., Jones, S. R., Owens, W. R. ( Assignee: Sundstrand Corporation) "Magneto-optic current sensor," U.S. Patent No. 4,947,107, August, 1990. 
[P13] Dupraz, J.-P. (Assignee: Alsthom), "Method of updating the scale factor of apparatus for measuring an alternating electric current by means of the Faraday effect," U.S. Patent No. 4,797,607, January, 1989.

[P14] Dupraz, J.-P. (Assignee: Alsthom), "Sagnac type optical fiber interferometer system," U.S. Patent No. 4,848,910, July, 1989.

[P15] Dupraz, J.-P., Thuries, E. (Assignee: GEC Alsthom SA), "Optical apparatus for measuring current in a grounded metal-clad installation," U.S. Patent No. 5,295,207, March, 1994.

[P16] Esman, R. D., Kersey, A.D., Marrone, M. J. (Assignee: The United States of America as represented by the Secretary of the Navy), "Polarization insensitive current and magnetic field optic sensor," U.S. Patent No. 5,434,501, July, 1995.

[P17] Esman, R. D., Kersey, A, D., Marrone, M. J. (Assignee: The United States of America as represented by the Secretary of the Navy), "Polarization insensitive current and magnetic field optic sensor," U.S. Patent No. 5,479,094, December 1995.

[P18] Feldtkeller, E.,(Assignee: Siemens Aktiengesellschaft (Berlin \& Munich, Germany)) "Magneto-optical measuring transducer for very high currents/voltages," U.S. Patent No. 3,980,949, September, 1976.

[P19] Feldtkeller, E., Harms, H, Papp, A.( Assignee: Siemens Aktiengesellschaft (Berlin and Munich, Germany)) "Magneto-optical high-voltage current measuring transducer," U.S. Patent No. 4,070,620, August, 1976.

[P20] Harms, H., Feldtkeller, E., (Assignee: Siemens Aktiengesellschaft (Berlin \& Munich, Germany)) "Magneto-optical high voltage current measuring transducer," U.S. Patent No. 4,070,622, September, 1976.

[P21] Ishiko, D., "Current and/or voltage detector for a distribution system," U.S. Patent No. 4,999,571, March, 1991.

[P22] Ishiko, D., Minemoto, H., Itoh, N. (Assignee: Matsushita Electric Industrial Co., Ltd) "Optical fiber sensor for measuring a magnetic fields or electric current and method for making the same," U.S. Patent No. 5,732,167, March,1998 .

[P23] Isozaki, T. Shinoda, K., Kawaguchi, T., Katsukawa, H., Nakanishi, K., Abe, H., Sakurai, Y.(Assignee: NGK Insulators, Ltd.), "System utilizing optical current sensors for detecting fault location in substation," U.S. Patent No. 5,243,293, Sept, 1993.

[P24] Kersey, A. D. (Assignee: The United States of America as represented by the Secretary of the Navy), "All-optical fiber Faraday rotation current sensor with heterodyne detection technique," U.S. Patent No. 5,063,290, November, 1991. 
[P25] Koide, H. (Assignee: Fuji Electric Co., Ltd) "Optical current transformer," U.S. Patent No. 5,488,291, January, 1996.

[P26] Koide, H., Yoshino, T.,(Assignee: Toshihiko Yoshino, Fuji Electric Co., Ltd.) "Optical current transformer," 5,780,845, July 14, 1998 .

[P27] Kozuka, Y., Kakizaki, Y., Sekiya, T., Abe, H. (Assignee: NGK Insulators, Ltd.), "Method and apparatus for optically measuring electric and magnetic quantities having an optical sensing head exhibiting the Pockels' and Faraday effects," U.S. Patent No. 4,933,629, June, 1990 .

[P28] Langeac, D., (Assignee: Commissariat a l'Energie Atomique), "Temperature and/or electrical intensity measuring apparatus based on the Faraday effect," U.S. Patent No. 4,563,639, January, 1986.

[P29] Lutz, D. R., Olson, G. A., Forsberg, G. B. ( Assignee: Minnesota Mining and Manufacturing Company), "Faraday effect current sensor having two polarizing fibers at an acute angle," U.S. Patent No. 5,051,577, September, 1991.

[P30] Lutz, D. R., MacDougall, T.W., Taylor, W.L., Varner, W. F., Wandmacher, R. A. (Assignee: Minnesota Mining and Manufacturing Company), "Faraday-effect sensing coil with stable birefringence and method of making same," U.S. Patent No. 5,553,173, September, 1996.

[P31] MacDougall, T.W., Dawson, J.W., Johnson, L.A. ( Assignee: Minnesota Mining and Manufacturing Company) "Optical fiber sensor with bend bifringence compensation, U.S. Patent No. 5,729,005, March, 1998.

[P32] Meier, M. (Assignee: ABB Research Ltd.), "Solid optical current sensor," U.S. Patent No. 5,583,428, Dec. 1996.

[P33] Meier, M. (Assignee: ABB Research Ltd.), "Sensor head for a fiber-optic current measuring device, ${ }^{,}$U.S. Patent No. 5,500,909, March, 1996.

[P34] Meier, M., (Assignee: ABB Research Ltd.), "Method for magnetooptic current measurement and magnetooptic current-measuring device," U.S. Patent No. 5,834,933, November, 1998.

[P35] Meunier, P.-L., Doriath, G., Razeghi, M. (Assignee: Thomson-CSF), "Integrated head for the measurement of magnetic fields and method of making this head," U.S. Patent No. 4,823,083, April, 1989.

[P36] Miller, R.C.,(Assignee: Westinghouse Electric Corp.) "Metering system for measuring parameters of high AC electric energy flowing in an electric conductor," U.S. Patent No. 4,578,639, March, 1986. 
[P37] Miller, R.C., Asars, J. A. (Assignee: Westinghouse Electric Corp.), "Drift compensation technique for a magneto-optic current sensor," U.S. Patent No. 4,683,421, July 1987.

[P38] Miller, R.C., Asars, J. A.(Assignee: Westinghouse Electric Corp.), "Optical measurement using polarized and unpolarized light," U.S. Patent No. 4,694,243, September 1987.

[P39] Miller, R. C., Asars, J. A. (Assignee: Westinghouse Electric Corp.), "Direct current magneto-optic current transformer" U.S. Patent No. 4,698,497, October 1987.

[P40] Miller, R. C. (Assignee: Westinghouse Electric Corp.), "Optical interface for a magneto-optical current transducer," U.S. Patent No. 4,745,357, May 1988.

[P41] Miller, R.C. (Assignee: Westinghouse Electric Corp.), "Optical interface for a magneto-optical current transducer" U.S. Patent No. 4,812,025, March, 1989.

[P42] Miller, R.C. (Assignee: Asea Brown Boveri, Inc.), "Optical system for a Faraday effect current sensor," U.S. Patent No. 4,916,387, April, 1990.

[P43] Mitsui, T., Tada, K., Kuhara, Y., Tatsumi, M. (Assignee: Sumitomo Electric Industries, Ltd.), "Magneto-optical converter utilizing Faraday effect," U.S. Patent No. 4,560,932, December 1985.

[P44] Nagatsuma, K., Matsumura, H., Suganuma, T., Olhta, N., Ando, K., Hosoe, Y., Sugita, Y., (Assignee: Hitachi, Ltd.), "Optical magnetic-field measuring apparatus having improved temperature characteristics," U.S. Patent No. 4,581,579, April, 1986.

[P45] Ochi, Naoki ( Assignee: Mitsubishi Denki Kabushiki Kaisha), "Optical current transformer," U.S. Patent No. 5,066,903, November 1991.

[P46] Ochi, N. (Assignee: Mitsubishi Denki Kabushiki Kaisha), "Optical instrument transformer," U.S. Patent No. 5,128,608, July, 1992.

[P47] Papp, A., Harms, H. (Assignee: Siemens Aktiengesellschaft), "Arrangement for the magneto-optical measurement of currents,"U.S. Patent No. 4,232,264, November, 1980.

[P48] Papp, A., Harms H. (Assignee: Siemens Aktiengesellschaft (Berlin and Munich, Germany)), "Method for magneto-optical current measurements," U.S. Patent No. 4,243,936, January, 1981.

[P49] Peier, D. Hirsch, H.(Asignee: MWB Messwandler-Bau A.G.), "Fiber optics arrangement for measuring the intensity of an electric current," U.S. Patent No. 5,237,265, August, 1993. 
[P50] Puech, C., Arditty, H., Papuchon, M.( Assignee: Thomson-CSF), "Interferometric optical fiber electric current measuring device," U.S. Patent No. 4,370,612, January 25, 1983.

[P51] Saaski, E. W., Lawrence, D. M. (Assignee: Metricor, Inc.), "Thermo-optical current sensor and thermo-optical current sensing systems," U.S. Patent No. 5,021,731, June, 1991.

[P52] Stierlin, R. ( Assignee: Asea Brown Boveri Ltd.), "Optical current transformer," U.S. Patent No. 5,304,920, April, 1994.

[P53] Tagawa, Y., Yamagiwa, T., Takahashi, G., Horide, A.( Assignee: Hitachi, Ltd., Chubu Electric Power Co., Inc.), "Three-phase collected type optical current transformer," U.S. Patent No. 5,410,243, April 1995.

[P54] Lee, Y.-Z., Lee, K. R. (Assignee: Industrial Technology Research Institute), "Method and apparatus for optically measuring electric current and/or magnetic field with temperature compensation," U.S. Patent No. 5,416,860, May 1995.

[P55] Tatam, R. P. (Assignee: British Technology Group Limited), "Apparatus and methods for measuring magnetic fields and electric currents," 5,450,006, September, 1995.

[P56] Lutz, D. R., MacDougall, T. W., Taylor, W.L., Varner, W. F., Wandmacher, R. A. (Assignee: Minnesota Mining and Manufacturing Company), "Faraday-effect sensing coil with stable birefringence,: U.S. Patent No. 5,463,312, October, 1995.

[P57] Berkcan, E. (Assignee: General Electric Company), "Electro-optical current sensing system and method for sensing and avoiding thermally induced measurement error therein," U.S. Patent No. 5,461,307, October 1995.

[P58] Ryczek, L. J., Hubbell, R. E. ( Assignee: Eaton Corporation), "Magneto-optical current measurement apparatus," U.S. Patent No. 5,502,373, March. 1996.

[P59] Sato, T., Takahashi, G., Inui, Y., (Assignee: Hitachi, Ltd.). "Method and apparatus for optically measuring a current," U.S. Patent No. 4,564,754, January 1986.

[P60] Tada, K., Kuhara, Y., Tatsumi, M., Mitsui, T. (Assignee: Sumitomo Electric Industries, Ltd.), "Magnetic field and current measuring device using a Faraday cell with a thin electrically conductive film substantially covering the Faraday cell," U.S. Patent No. 4,608,535, August, 1986.

[P61] Tangonan, G., Morrison, R.J.,Wysocki, J.A, Persechini, D.L. ( Assignee: Hughes Aircraft Company), "Fiber optic transducer for measuring current or magnetic field," U.S. Patent No. 4,348,587, September, 1982.

[P62] Ulmer, Jr., E. A. (Assignee: Square D Company), "Electric current sensor using the Faraday 
effect. " U.S. Patent No. 4,894,608, January 1990.

[P63] Ulmer, Jr., E. A. (Assignee: Square D Company), "Method of eliminating the effects of birefringence from the detection of electric current using Faraday rotation" U.S. Patent No. 5,008,611, April, 1991.

[P64] Ulmer, Jr., E.A., Meyer, T. J. (Assignee: Square D Company), "Ring optical current transducer," U.S. Patent No. 5,124,634, June, 1992.

[P65] Ulrich, R., Rashleigh, S.C. (Assignee: Max-Planck-Gesellschaft zur Forderung der Wissenschaften e.V), "Fibre optical arrangement for measuring the intensity of an electric current," U.S. Patent No. 4,255,018, March, 1981.

[P66] Ulrich, R., Rashleigh, S.C. (Assignee: Max-Planck-Gesellschaft zur Forderung der Wissenschaften e.V.), "Fiber optics device for measuring the intensity of an electric current utilizing the Faraday effect," U.S. Patent No. 4,539,519, Sept. 1985.

[P67] Vaerewyck, E.G., Anderson, A.E. ( Assignee: Westinghouse Electric Corp) "Electric motor and transformer load sensing technique," U.S. Patent No。 4,363,061 December 7, 1982.

[P68] Vaerewyck, E. G., Anderson, A. E. (Assignee: Westinghouse Electric Corp.) "Electric motor and transformer load sensing technique," U.S. Patent No. 4,428,017, Jan. 1984.

[P69] Vaerewyck, E. G., Chen, C.-L., Asars, J. A. (Assignee: Westinghouse Electric Corp.), "Faraday current sensor with fiber optic compensated by temperature, degradation, and linearity," U.S. Patent No. 4,613,811, September 1986. 


\section{Standards}

[S1] IEEE Standard C57.13-1993, IEEE Standard Requirements for Instrument Transformers

\section{ABSTRACT:}

Electrical, dimensional, and mechanical characteristics are covered, taking into consideration certain safety features, for current and inductively coupled voltage transformers of types generally used in the measurement of electricity and the control of equipment associated with the generation, transmission, and distribution of alternating current. The aim is to provide a basis for performance, interchangeability, and safety of equipment covered and to assist in the proper selection of such equipment. Accuracy classes for metering service are provided. The test code covers measurement and calculation of ratio and phase angle, demagnetization, impedance and excitation measurements, polarity determination, resistance measurements, short-time characteristics, temperature rise tests, dielectric tests, and measurement of open-circuit voltage of current transformers.

\section{[S2] IEC 186-1987, Current Transformers}

\section{ABSTRACT:}

This standard applies to new voltage transformers for use with electrical measuring instruments and electrical protective devices at frequencies from $15 \mathrm{~Hz}$ to $100 \mathrm{~Hz}$.

The general requirements of this chapter apply to all voltage transformers, but, for certain types, for example capacitor voltage transformers, the requirements are subject to the modifications stated in the appropriate chapter.

Although the requirements relate basically to transformers with separate windings, they are also applicable, where appropriate, to auto-transformers. The standard does not apply to transformers for use in laboratories.

[S2a] IEC 186(Amend. 1)-1990, Current Transformers - Amendment 1

[S2b] IEC 186(Amend. 2)-1995, Current Transformers - Amendment 2 
? 
